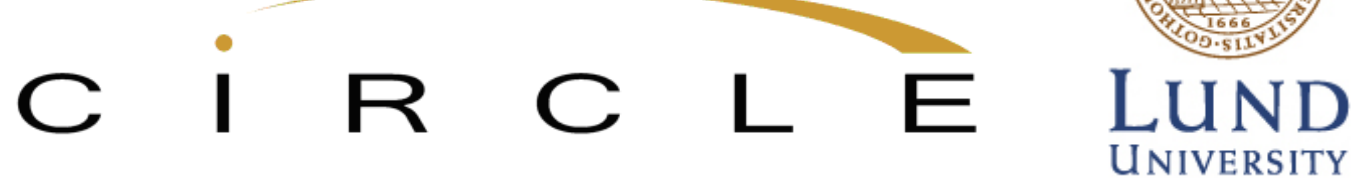

\title{
Does Mobility across Universities Raise Scientific Productivity?
}

Olof Ejermo (olof.ejermo@ekh.lu.se)

Department of Economic History and CIRCLE, Lund University, Sweden Claudio Fassio (claudio.fassio@fek.lu.se)

Dept. of Business Administration and CIRCLE, Lund University, Sweden

John Källström (john.kallstrom@nek.lu.se)

Department of Economics and CIRCLE, Lund University, Sweden

Papers in Innovation Studies

Paper no. 2019/14

This is a pre-print version of paper, which has been submitted to a journal.

Centre for Innovation, Research and Competence in the Learning Economy (CIRCLE)

Lund University

P.O. Box 117, Sölvegatan 16, S-221 00 Lund, SWEDEN

http://www.circle.lu.se/publications 
WP 2019/14

\title{
Does Mobility across Universities Raise Scientific Productivity?
}

Olof Ejermo, Claudio Fassio, John Källström

\begin{abstract}
Using a highly comprehensive new dataset on Swedish researchers, we investigate the effects of interuniversity mobility on researcher productivity. Our study suggests substantial gains from mobility on scientific output. We find that mobility induces a long-lasting increase in a researcher's publications by $29 \%$ and citations by $50 \%$. Moreover, we analyze the factors that are likely to have an impact on the overall effect of mobility: the interaction of mobility and promotion, the importance of the status of the destination university, as well as the role of the specific disciplinary field of mobile researchers. The empirical analysis addresses selection using inverse probability treatment censoring weights.
\end{abstract}

Keywords: Economics of science; mobility; scientific productivity; university JEL Codes: O31; I23; J24

Disclaimer: CIRCLE does not take any responsibility for opinions and views expressed by the authors in this paper. 


\title{
Does Mobility across Universities Raise Scientific Productivity?
}

\section{OLOF EJERMO, $\uparrow, \uparrow$ CLAUDIO FASSIO, + , ๆ and JOHN KÄLLSTRÖM, $\S, \uparrow$}

$\dagger$ Department of Economic History, School of Economics and Management, Lund University, Lund University, Lund, Sweden (olof.ejermo@ekh.lu.se)

\$ Department of Business Administration, School of Economics and Management, Lund University,Lund, Sweden (claudio.fassio@fek.lu.se)

$\S$ Department of Economics, School of Economics and Management, Lund University, Box 7082, SE-22007Lund, Sweden (john.kallstrom@nek.lu.se)

I Centre for Innovation, Research and Competence in the Learning Economy, Lund University, Lund, Sweden

\begin{abstract}
Using a highly comprehensive new dataset on Swedish researchers, we investigate the effects of interuniversity mobility on researcher productivity. Our study suggests substantial gains from mobility on scientific output. We find that mobility induces a long-lasting increase in a researcher's publications by $29 \%$ and citations by $50 \%$. Moreover, we analyze the factors that are likely to have an impact on the overall effect of mobility: the interaction of mobility and promotion, the importance of the status of the destination university, as well as the role of the specific disciplinary field of mobile researchers. The empirical analysis addresses selection using inverse probability treatment censoring weights.
\end{abstract}

\section{JEL classification numbers}

O31, I23, J24

\section{Keywords}


Economics of science, mobility, scientific productivity, university

\section{Introduction}

The lack of interuniversity mobility among researchers has attracted substantial interest from policymakers because it is often claimed that low mobility across academic institutions hampers the diffusion of ideas, leading to an inefficient allocation of human capital and to intellectual inbreeding (European Commission 2012, OECD 2008). Many European countries might suffer from such problems, as indicated by the high share of faculty members who received their $\mathrm{PhD}$ at the same institution in which they work (Horta et al. 2010). This suggests, in turn, that Europe, in particular, would benefit from a more integrated academic labor market, as less efficient knowledge production also implies negative consequences for economic growth, given the important role that universities play in economic development (Foray and Lissoni 2010).

In this paper, we investigate the importance of mobility by examining academic researchers' mobility across Swedish universities to see whether they become more scientifically productive and under what conditions. Sweden is an interesting empirical case, as its academic system is high performing, with several universities ranked near the top worldwide and relatively high levels of public funding (Shanghai Jiao Tong University 2017, Times Higher Education 2018). At the same time, the system has historically displayed low levels of mobility across institutions. This might leave room for upgrading efficiency precisely through researchers' mobility.

We examine the effects of mobility on scientific productivity in terms of both publication output and the quality of scientific output, gauged through citation-weighted publication output. We analyze which factors are likely to have an impact on the overall effect of mobility, including 
interaction between mobility and promotion, the importance of the status of the university of destination, and the specific disciplinary field of mobile researchers.

The individual level is a useful unit of analysis for understanding whether policy should promote mobility within academic systems, as it can give us precise and direct estimates of the gains from mobility, and many confounding factors can potentially be controlled for. However, no solid empirical evidence exists yet on the returns to mobility for academic researchers. A challenge in the measurement of such an effect is, in addition to the substantial data collection requirements, an empirical one related to the fact that highly productive researchers are also more likely to be mobile (Zucker et al. 2002). This means that mobility can have a positive effect on productivity but also that the reverse effect — from productivity to mobility — cannot be ruled out (Hoisl 2007).

Moreover, other factors are likely to influence the impact of mobility on scientific productivity. In many cases, individuals move to a new university to obtain a promotion that would not be available at their current institution. Because researchers' promotions to a higher rank in the academic system can also have an impact on their productivity, the effect of mobility ideally should be separated from the effect of promotion. Also, the status of universities plays a role in mobility patterns, because researchers often prefer to move to more prestigious universities. Higher prestige tends to be associated with more resources, which in turn might lead to better research outcomes. This means that an individual who 'descends' in the university hierarchy can be expected to suffer a reduction in both time and resources for research and vice versa for those who move up the hierarchy. Finally, mobility might have different effects across different disciplines. In some fields, especially in the hard sciences, moving to an environment with better research facilities or higher investment in labs and equipment can substantially increase performance, while this is less likely to be relevant in the social sciences or the humanities. 
We conduct our empirical analyses using a highly comprehensive new database on publications and citations of more than 35,000 Swedish university researchers who were active in the period 2002-2012, which is based on employer-employee and university registers at Statistics Sweden. These data allow us to follow individuals over time and to observe a large range of individual characteristics, controlling for confounding factors and analyzing individual heterogeneity. The data also enable us to identify researcher moves between academic institutions as well as publication output.

In our analyses, we address endogeneity that stems from reverse causality through the method of inverse probability treatment censoring weights (IPTCW; Robins 2000). The method assigns each individual a weight equal to the inverse probability of being treated, utilizing an individual's history of observables (Azoulay et al. 2009, Buenstorf 2009), thereby allowing us to estimate the mobility effect over the full sample of researchers. In robustness estimations, we adopt instead a matched sample approach, in which we use a nonparametric coarsened exact matching (CEM) algorithm to identify an appropriate control group.

Our estimations (both IPTW and CEM) reveal that mobility leads to a lasting increase in both the quantity and quality of publication output of researchers who move (here called 'movers'), compared with those who remain (here called 'stayers'). In our preferred estimations, we find that the publication rate increases approximately $29 \%$ and citations increase $50 \%$. We also find that promotion by itself does not explain the positive effects of mobility, even though promotion is much more common among movers than among stayers. Moreover, using the university status of the destination institution as a proxy for host institution quality, we find that only moves to a university of high quality have an impact, which is in line with an earlier study on the UK (Fernández-Zubieta et al. 2015a). Finally, when we distinguish among different disciplines, we 
find that moving has a positive effect for researchers in all disciplines but the humanities and the social sciences.

The paper contributes to the existing literature in several ways. First, we provide the first country-level analysis of the effect of researchers' mobility on productivity, encompassing most academic researchers in the national academic system, instead of focusing on a specific sample or discipline. This adds to the generalizability of our results. Second, the longitudinal dimension of our dataset and the richness of individual characteristics, coupled with our chosen estimation strategy, allows us to separate the effect of mobility from other confounding factors and to take selection issues into account. Finally, we shed light on how specific factors, such as promotion, university hierarchy, and disciplinary field, influence the mobility effect for individual researchers.

\section{Job mobility and researcher productivity}

Although the effect of productivity on mobility (especially for highly productive individuals) is fairly established, the mobility effect on scientific productivity is still a matter of dispute, and evidence remains scarce. Some studies, mostly focused on the US academic system, find that job mobility increases the publishing performance of researchers. For example, Azoulay et al. (2011) find a positive effect of mobility on productivity and citations of scientists in the life sciences, suggesting that mobility fosters the diffusion of knowledge geographically, as indicated by a higher number of citations that mobile scientists obtain from colleagues at recipient institutions. Similarly, Dubois et al. (2014), using a large sample of mathematicians active all over the world, find a positive effect of mobility on research productivity. Using data on the top 100 scientists in terms of publications in seven different disciplines, Halevi et al. (2016) also find that mobility among departments generally has a positive effect on publications and citations. Similarly, in Di Lorenzo and Tartari (2014), who study a sample of 80 research active academics working in UK life science departments, mobility has a positive effect on scientific productivity. 
The impact of mobility on productivity depends on institutional factors related to the specific workings of national academic labor markets. Although most results focused on the Anglo-Saxon context find a positive effect of mobility on academic performance, existing evidence from continental and Southern Europe show a different picture. For instance, Bolli and Schläpfer (2015) find that interinstitutional mobility has no effect on the publication outcomes of economists in Austria, Germany, and Switzerland, in 2006-2008.

As explained by Fernández-Zubieta et al. (2015b) and Stephan (2012), most mobility within an academic system comes from nontenured staff (typically postdoctoral researchers) who have been unable to secure a permanent position and are often required to change institution at the end of their contracts. In a study on German postdoctoral researchers in economics and management, Bäker (2015) finds that mobility induces a negative short-term effect on scientific productivity, especially when researchers' social capital is strongly linked to the department with which they were originally affiliated. Also in the Anglo-Saxon context, some studies find no evidence of a positive effect of mobility on research outcome. In a longitudinal study of academic careers among UK academics, Fernández-Zubieta et al. (2015a) find no evidence of a positive effect of mobility on academic performance. By contrast, they find that downward mobility (mobility to lessprestigious institutions) can reduce researcher productivity.

At the same time, many European academic systems, including the Swedish system, do not require researchers to be mobile, by, for example, leaving their university after receiving a $\mathrm{PhD} .{ }^{1}$ This can lead to academic inbreeding. Again, the empirical evidence is mixed. As shown by CruzCastro and Sanz-Menéndez (2010) using a sample of Spanish scientists, researchers with a PhD from the same institution at which they are currently active do not perform worse than $\mathrm{PhD}$ holders

\footnotetext{
${ }^{1}$ Germany is an important exception, because researchers there must change university after completing $\mathrm{PhD}$ studies to attain a professorship (Bäker 2015).
} 
who are not 'inbred.' Other research suggests that concern over inbreeding is not limited to Europe. Horta et al. (2010) focus on the impact of hiring PhDs trained in the department that granted the person that $\mathrm{PhD}$ on academic performance in Mexico. The empirical results show that inbred academic researchers generally show lower performance in terms of scholarly output than academics who change their affiliation at least once over the course of their career. Morichika and Shibayama (2015) find similar results among Japanese researchers.

\section{Data}

We constructed a dataset of Swedish academics following a three-step procedure. In the first step, we sent requests to all Swedish universities and university colleges (defined below) asking for lists of all their staff whose position requires research - that is, professors, associate professors, postdocs, and $\mathrm{PhD}$ students ${ }^{2}$ - going as far back in time as possible. These staff lists are publicly available in Sweden, and any government body (most universities in Sweden are state run) are required by law to release them to researchers upon request. Each listed individual has a social security number, giving each researcher a unique identifier even if the individual appears on several universities' staff lists. The universities also supplied information about first and last names, affiliations, and e-mail addresses of the researchers to enable us to match them with publication records. In the end, out of the 28 universities and university colleges we contacted, 25 responded and sent us the requested information.

In the Swedish system, a distinction exists between full research universities (universitet) and university colleges (högskola; pl. högskolor). The latter have far fewer research resources allocated per researcher. For instance, universitet receive a bonus for $\mathrm{PhDs}$ completed with support from

\footnotetext{
${ }^{2}$ A large group of staff is labelled "Other researchers and teaching staff." Even though those in this group do not have a formal academic position, many have a $\mathrm{PhD}$ and publish with an academic affiliation, so we include them in our analysis. The staff category consists of, for example, lab assistants and research engineers.
} 
government block grants, whereas högskolor do not. Moreover, although all faculties are represented in universitet, högskolor only include one or a few faculties. ${ }^{3}$ In addition, research and teaching staff at universitet have less teaching and more research time at their disposal, mainly because of government resource allocation decisions. ${ }^{4}$ However, in practice, some university colleges that are called högskola are de facto universitet. The exceptions are three specialized technical and medical högskolor: the Royal Institute of Technology (KTH), Chalmers University of Technology, and the Karolinska Institute (KI). These are, for all intents and purposes, universitet even though they have only one faculty. Online Appendix Table A1 lists the academic divisions in our sample and whether they are considered universitet or högskola in our study.

In the second step, with the assistance of Fraunhofer ISI in Germany, we match the lists to author IDs as given in the Scopus database, using combinations of their names, affiliations, and email addresses that appear on publications and the staff lists. The Scopus database starts in 1996, and the staff lists cover different periods (see Online Appendix Table A1 for the years covered by each responding university's staff lists), leaving us with the period of analysis 2002-2012. For this period, we have a sample of 70,202 unique researchers employed in the university sector in Sweden, of which we can match 35\%, or 25,020 individuals, to an author ID in Scopus. This sample of researchers, accounts for around $85 \%$ of the publications associated with a Swedish author ID in Scopus that could potentially be matched by Fraunhofer ISI. For our matched researchers, Fraunhofer ISI added information on the number of Scopus publications by year. For the period

\footnotetext{
${ }^{3}$ From here on, the term "faculties" is used in this paper to refer to broad subject fields: i.e., social sciences, humanities, engineering and technology, medicine, and the natural sciences.

${ }^{4}$ According to the latest available figures, an average employee at universities had $43.8 \%$ research time in 2011 , whereas staff working at university colleges with/without any PhD education had 20.9/24.8\% research time (SCB 2017).
} 
2002-2012, we have the number of publications for each matched researcher. We count entire publications, rather than divide publication counts by the number of authors, and use the number of citations in a three-year window following the publication of an article as our measure of publication quality.

In the last step, we used researchers' social security numbers to link them to employeremployee and ancillary university-employee lists available from Statistics Sweden. This connection to register data gives us access to a wide range of data on researchers, including demographic and job characteristics. The matching of yearly publication output with university register and Swedish Statistics data allows us to infer whether an individual has changed university. We define mobility as a change in a researcher's main university employer from one year to the next.

One challenge is that not all academic researchers show up in Scopus publications; for example, they might publish in publication types that are rarely covered by Scopus, such as books, anthologies, or journals that publish in the national language (e.g., Swedish). This issue is more pressing in the social sciences and humanities. To address this issue, we use data from Statistics Sweden to predict the probability of matching a Swedish researcher with a publication in the Scopus database based on a wide range of individual-level characteristics. Indeed, to make our sample representative, we also want to include researchers who have no publications, but we need to ensure that the only reason we could not match those researchers is that they did not publish in Scopus-listed journals (and not for other reasons, such as homonymy, which prevented matching). Hence, we included as 'nonpublishing researchers' individuals who were not matched to any Scopus publication but, according to our estimation, have a very low predicted probability $(<0.2)$ of being matched using our procedure. These individuals are likely to be researchers who truly do not have any publications listed in Scopus. This allows us to add an additional 10,341 researchers 
from the register data. The result is a sample of 35,361 researchers (i.e., about $50 \%$ of all university researchers). ${ }^{5}$ For further details on the construction of the database and an analysis showing that it constitutes a representative sample of Swedish researchers with publications, see Ejermo et al. (2016).

We add some further restrictions on the sample for analysis. First, we omit all $\mathrm{PhD}$ students from the sample, including those who transition to a $\mathrm{PhD}$ student position from another researcher job. It frequently happens that someone either during their $\mathrm{PhD}$ studies, or after graduating, moves to another academic division at the end of their studies or leaves academia. Hence, mobility among $\mathrm{PhD}$ students involves a different, largely unobservable, selection process that follows a different rationale than it does at later career stages (cf. Nisticò 2018). Importantly, in our empirical analysis we use our observation of various characteristics that determine mobility in our data, further arguing that it allows us to account for selection effects. It is crucial for us to observe past productivity in terms of publications and citations, which, as we discuss in more depth below, are important determinants of future mobility. However, $\mathrm{PhD}$ students are likely to lack such paper trails simply because remaining in academia after receiving a $\mathrm{PhD}$ involves a selection into a research career. This makes selection into mobility for a $\mathrm{PhD}$ student determined to a greater extent by unobserved factors (to the econometrician), such as promising 'papers in the pipeline,' which in turn implies a higher degree of omitted-variable bias for this group.

Second, although internationally mobile scientists are often among the most productive (Franzoni et al. 2014), we omit scientists who are internationally mobile during the sample period by dropping individuals who emigrate from or immigrate to Sweden, because we cannot observe

\footnotetext{
${ }^{5}$ We later check the robustness of our results by dropping "nonpublishing researchers" from the sample.
} 
the productivity of internationally mobile researchers while they are abroad. By doing this, we lose $6 \%$ of the observations in our sample period.

Third, we omit from our sample movers who move more than once during the 2002-2012 period. We refer to them as 'multiple movers.' It is not clear exactly how to account for the effects of different numbers of moves, that is, whether effects from second moves are qualitatively the same as those from first moves. Moreover, multiple movers differ from their nonmobile counterparts. Thus, including them in the analysis would introduce more heterogeneity between movers and stayers and would make the interpretation of our findings more difficult. Multiple movers comprise a relatively small share of mobile researchers (about 10\%); in fact, a robustness analysis reveals that including multiple movers does not change our main results in any qualitatively significant way. ${ }^{6}$

\section{Empirical strategy}

\section{Econometric specification}

As a first step to disentangle the direction of causality between mobility and scientific productivity, we specify Poisson fixed-effects difference-in-differences regressions. Our main estimated equation relates mover $i$ 's scientific productivity in year $t$ in the following way:

$E\left[y_{i, t}\right]=\operatorname{Exp}\left[\beta_{1}\right.$ PostMob $\left._{i, t}+\beta_{2}{ }^{\prime} \boldsymbol{X}_{i, t}+\gamma_{i}+\delta_{t}+\varepsilon_{i, t}\right]$,

where $y_{i, t}$ is the dependent variable measuring the quantity or quality of publications measured as raw publication counts and citations, respectively; PostMo $b_{i, t}$ is a typical difference-in-differences

\footnotetext{
${ }^{6}$ Those results create an indicator in which multiple movers have a value of 1 for all observations after the move. Results are available from the authors on request.
} 
indicator that becomes 1 after a move; $\boldsymbol{X}_{i, t}$ is a vector of time-varying characteristics including the number of children, whether s/he is married or cohabitating (cf. Azoulay et al., 2016), experience measured as the number of years since graduation; $\gamma_{i}$ and $\delta_{t}$ are individual- and time-fixed effects, respectively; and $\varepsilon_{i, t}$ is an idiosyncratic (robust) error term. We include individual-level fixed effects, $\gamma_{i}$, to capture time-invariant heterogeneity, such as intrinsic differences in ability or motivation, that affect publishing productivity and the likelihood of mobility. Lastly, including calendar-year-fixed effects, $\delta_{t}$, captures general time trends that affect publishing. Our main coefficient of interest is $\beta_{1}$, which is the average treatment effect of mobility among movers.

Our dependent variable is the number of publications or, alternatively, the number of citations each year. We estimate a fixed-effects (Quasi-ML) Poisson model to take the nonnegative countdata nature of our data into account (Wooldridge 1999). ${ }^{7}$ The main advantage is that a Poisson model allows for highly skewed distributions of nonnegative outcomes that would otherwise bias ordinary least squares (OLS) estimates. By clustering them at the individual level, we can ensure that the standard errors are consistent even if the underlying data-generating process is not Poisson (Cameron and Trivedi 2010).

\section{Threats to identification}

In our empirical investigation, the threats to identification of the effect of mobility on publication and citation rates stem from the confounding effects of selection and treatment (mobility). The literature on mobility has shown that higher individual research productivity makes academics and other knowledge workers more likely to move (Azoulay et al. 2016, Hoisl 2007). To the extent that

\footnotetext{
${ }^{7}$ We also ran our specification using standard ordinary least squares (OLS) to check the robustness of the estimates. The results (available from the authors on request) show that they are very stable.
} 
such positive selection varies over time for an individual, it is likely to bias fixed-effects estimations.

In Table 1, we show summary statistics of 'stayers' (researchers who remain at the same university after graduation) and 'movers' (individuals who change their main university of employment at least once) in our sample. We find 1,270 movers, who each account for one move event by construction. As predicted, the table shows that movers have a more productive track record. Movers are associated with 0.53 more publications per year on average in the year of moving and have 3.05 more citations per year on average compared to stayers. They also more frequently hold tenured positions ( $3 \%$ more likely to be professors and $8 \%$ more likely to be associate professors), although a shorter period has elapsed since their degree (on average, 1.69 fewer years since graduating). Mobile researchers are also more likely to have children (18\%) and to be married or be cohabitating with a partner $(6 \%)$.

\section{INSERT TABLE 1 ABOUT HERE}

We employ two strategies to deal with the potentially endogenous relationship between publication and mobility. The first relies on the so-called inverse probability of treatment censoring weights (IPTCW), while the second is based on coarsened exact matching (CEM). In order to save space and because we consider IPTCW to be more representative of a general effect, we present only the IPTCW analysis in the main text. The two methods are discussed in Online Appendix B, and results using CEM are presented in Online Appendix C.

\section{Inverse probability of treatment censoring weights}

The standard way to account for selection into mobility would be to find an instrumental variable (IV) that explains mobility but is unrelated to a researcher's own productivity. However, in the 
absence of such an instrument, our primary choice to deal with self-selection into mobility is the inverse probability of treatment censoring weights (IPTCW; Robins 2000). The basic idea behind this method is to give 'unexpected' movers - individuals whose move predicted on observables is less likely - a larger weight in the ensuing regressions than that of individuals whose move is more likely. Unlike fixed-effects estimations, IPTCW allows us to recover average treatment effects even in the presence of time-varying selection into treatment, that is, selection that correlates with past and future values of the dependent variable and other as below confounders. To the extent that we can account for selection by means of observables, the strategy mimics an IV approach in such a way that it creates a 'pseudo-population,' in which an unexpected mover is more likely to move, without making any strong assumption on the functional form of the relationship.

We follow the method of Azoulay et al. (2009) and Buenstorf (2009) in constructing stabilized weights that take into account both endogenous selection into treatment and censoring (exiting the sample). In short, the treatment weights are defined as:

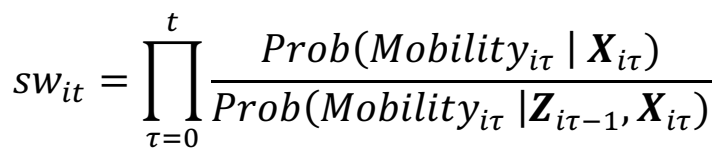

And the censoring weights are defined as:

$$
S W_{i t}^{*}=\prod_{\tau=0}^{t} \frac{\operatorname{Prob}\left(E x i t_{i \tau} \mid \boldsymbol{X}_{i \tau}\right)}{\operatorname{Prob}\left(\operatorname{Exit}_{i \tau} \mid \boldsymbol{Z}_{i \tau-1}, \boldsymbol{X}_{i \tau}\right)},
$$

where $\boldsymbol{X}_{i \tau}$ and $\boldsymbol{Z}_{i \tau-1}$ are matrices containing time-invariant and time-varying confounders associated with mobility. In our case, $\boldsymbol{X}_{i \tau}$ comprises age, age squared, gender, number of children, and marital status, as well as discipline, university, staff category, and year-fixed effects. The main selectors into mobility, $\boldsymbol{Z}_{i \tau-1}$, are publication and citation flows in $t-1$ as well as cumulative publications and citations in $t-2$. Weighting by $s w_{i t}$ creates a 'pseudo-population' in which 
$Z_{i, t}$ no longer determines selection into treatment and the causal impact of mobility is the same as in the original population. The numerators and denominators are estimated by means of logit regressions. ${ }^{8}$ The estimation of the denominator/numerator of $s w_{i t}$ for scientist $i$ in year $t$ is $\prod_{\tau=0}^{t}\left(1-p_{i t}\right)$ if scientist $i$ did not move by year $t$, and $\prod_{\tau=0}^{t-1}\left(1-p_{i t}\right) \times p_{i t}$ if scientist $i$ moved in $t$, in which $p_{i t}$ is the predicted probability obtained from logit estimations. Estimation of $s w_{i t}^{*}$ proceeds in the same fashion. The final IPTCW weights are defined as $s w_{i t} \times s w_{i t}^{*}$. Note that because the weights vary over time, they cannot be combined with fixed effects.

As mentioned, the main advantage of the IPTCW approach is that it will produce unbiased estimates if no unobserved time-varying confounders affect the propensity to be mobile. However, this is a strong assumption. For instance, as we discussed above, the hiring department is likely to observe 'papers in the pipeline' among the potential hires, unobserved to us but whose existence will affect hiring chances and hence the likelihood of being mobile. However, as suggested by Azoulay et al. (2009), the method performs well when (i) the estimations are based on a large set of observables (and to the extent that these observables are correlated with unobservable confounders); (ii) subjects are drawn from the same labor market; and (iii) the dependent variable is measured similarly in the control and treatment groups. All three of these conditions are fulfilled in the current context.

\section{Results}

We analyze the effects of moving in two sections. First, we include all moves in our analyses (i.e., moves including any type of academic position, except moves to/from a $\mathrm{PhD}$ student position, as discussed above). We refer to this as our main effect of mobility. Next, we investigate the heterogeneous effects of mobility, differentiating between moves with and without promotions,

\footnotetext{
${ }^{8}$ We report these estimations in Online Appendix D.
} 
moves up and down the university hierarchy (up = from a högskola to a universitet and down $=$ from a universitet to a högskola), and differences across disciplinary fields.

\section{Main effect of mobility}

Table 2 presents the results of the main analysis. Columns (1) and (3) presents the results of the IPTCW estimations on, respectively, the number of publications and of citations; columns (2) and (4) presents the results obtained with a simple fixed-effects (Quasi-ML) Poisson model on the same dependent variables. We find positive effects from mobility on the quantity of publications and the quality of publications in all models. The IPTCW estimates are markedly higher than in the fixedeffects regressions, indicating an increase in publications and citations of $29 \%$ and $50 \%$, respectively, for movers. For the matched sample, shown in Online Appendix C, the increases are slightly lower, $14 \%$ and $29 \%$ respectively, but still strongly significant. We also conducted our IPTCW analyses by dropping individuals who had zero articles published. This did not change those results in any substantive way. However, dropping these individuals brings the estimated IPTCW coefficients closer to the fixed effects. This is intuitive, because individuals with zero articles published or cited are automatically dropped from the individual-fixed effects specifications. ${ }^{9}$

These results tell us that mobility has a positive effect on productivity for individual researchers who move from one institution to another in the Swedish academic system.

\section{INSERT TABLE 2 ABOUT HERE}

We also run our main specifications using leading and lagged indicators of the move, which help us discern whether movers are publishing more or less than stayers before they move. The

\footnotetext{
${ }^{9}$ These results are available from the authors on request.
} 
lagged indicators allow us to explore the duration and time pattern of the mobility effect. We plot the point estimates of the leading and lagged indicators from Poisson estimations with IPTCW in Figure $1 .{ }^{10}$ Generally, we note that our preferred specification, using the IPTCW method, is successful in removing any pretreatment differences, regarding the validity of this method. In addition, each method reveals that the effects of mobility last up to eight years after the move, suggesting that mobility has a long-lasting effect on productivity.

\section{INSERT FIGURE 1 ABOUT HERE}

\section{Heterogeneous effects of mobility}

We now turn to how the main effects of mobility differ by the type of move. First, we investigate the role of career transitions (promotions) in the effects of mobility, looking specifically at the effect of moving up or down the career ladder in academia. Second, we investigate whether mobility up the Swedish university hierarchy is important in determining the size effect of mobility. Previous studies indicate that a move has a positive impact on scientific output, especially if it involves upward mobility in the university hierarchy (Fernández-Zubieta et al. 2015a), which suggests that moving to better research environments has a positive impact on researcher productivity. Finally, we check whether the effects of mobility vary by field. In Online Appendix $\mathrm{C}$, we present the same set of analyses using the CEM matched sample: all results are perfectly in line with those displayed in the paper.

\section{Career ladders and mobility}

Earlier literature has highlighted how research opportunities vary by position (e.g. Sabatier 2012). One of our hypotheses is that the mobility-productivity effect is closely tied to promotions. We

\footnotetext{
${ }^{10} \mathrm{We}$ also ran these estimations using Poisson fixed effects with and without using the matched sample. These results are available in Online Appendixes A and D, respectively.
} 
consider this especially important in systems with low mobility rates, as in the Swedish case, in which promotions are likely to be a driver of mobility. Indeed, Online Appendix Table A2, which tabulates position transitions subdivided by movers and stayers, confirms that the probability of a change in position is more common among movers than among stayers.

To analyze the general role of moving up or down the academic career hierarchy, we construct indicators: (i) 'Promotion,' which equals 1 the first time (and afterward) a researcher is observed to have moved up the career ladder; and (ii) 'Demotion,' which equals 1 the first time (and afterward) an academic is observed to have moved down the career ladder. ${ }^{11}$ The definition of promotion and demotion involves a comparison of positions in two years, as follows. For associate professors, we consider a transition to full professorship a promotion. For postdocs, we define a transition to either a full or associate professorship a promotion. Finally, for other researchers, any transition to a full or associate professorship or becoming a postdoc is considered a promotion. According to this definition, full professors, who already are at the peak of the career ladder, cannot be promoted. By contrast, demotions are, for professors, any transition to another type of position; for associate professors, a transition to being a postdoc or to 'other researcher' category; for postdocs, it is a transition to the 'other researcher' category. In this context, 'other researchers,' by definition, cannot be demoted. ${ }^{12}$

In Table 3, we investigate the role of moving up or down the academic career hierarchy and mobility. To be able to distinguish the role of mobility on productivity from that of career transitions, we introduce a new indicator, 'Stay,' which equals 1 for researchers who never move.

\footnotetext{
${ }^{11}$ This coding is done such that a researcher is never demoted after a promotion and never promoted after a demotion.

${ }^{12}$ Because being a guest researcher by definition is a short-term type of mobility, we exclude results for this category.
} 
This indicator is used, in combination with the 'PostMob' indicator and the 'Promotion' and 'Demotion' dummies, to create four new indicators: 'PostMob \& No Promotion/Demotion,' 'PostMob \& Promotion,' 'Stay \& Promotion,' 'PostMob \& Demotion,' and 'Stay \& Demotion.' The indicator 'PostMob \& No Promotion/Demotion' equals 1 each year after a researcher moves if that move is not associated with a change in career position; otherwise, it is 0. Conversely, 'PostMob \& Promotion' equals 1 each year after a mobility event when it is associated with a promotion, and 0 otherwise. 'Stay \& Promotion' equals 1 for each year after the first observed promotion for researchers who never move. Correspondingly, 'PostMob \& Demotion' equals 1 each year after the first observed demotion if associated with a move in the same year and 'Stay \& Demotion' equals 1 for researchers who are demoted and do not move. The baseline category is not moving and not being promoted. An individual is allowed, in our coding, to change status only once to any of the other categories. ${ }^{13}$

\section{INSERT TABLE 3 ABOUT HERE}

Again, we display the estimates obtained using (i) the IPTCW method (the preferred analysis method) and (ii) fixed effects. The effect of mobility per se, is still positive and significantly different from zero in all specifications, and the magnitude of the coefficients is in line with the results in Table 2. Moreover, the results indicate that a move coupled with a promotion leads to a higher impact on productivity, but further t-tests on the equality of coefficients reveal that the effect is not significantly different from the effect of mobility without promotion. This is true for both publications and citations. We also find that researchers who remain and are promoted experience a positive and significant effect on publications and citations. The magnitude of the coefficients is

\footnotetext{
${ }^{13}$ Thus, an individual who first moves and is promoted only later will only be coded as "PostMob \& No Promotion/Demotion."
} 
equal or slightly lower than the coefficient for mobility without promotion, while it is always lower than the effect of mobility coupled with promotion. However, t-tests on the equality of coefficients indicate that the difference is significantly different only in column (2). By contrast, whenever a demotion is involved, the effect on productivity is never significantly different from 0.

In sum, we find that movers who are simultaneously promoted do not show a statistically significant different publication rate than other movers. This suggests that it is mainly the move itself that explains the effect, not promotion. Moreover, the results suggest that individuals who do not move but are promoted are equally able to increase their productivity over time, although a slightly lower effect is seen on citations. This last result is in line with previous findings by CruzCastro and Sanz-Menéndez (2010) in the Spanish context, according to which careers at the same academic institution are not necessarily associated with lower publication outcomes.

\section{Moving up the university hierarchy}

An additional factor pointed out in the literature is that mobility can have a positive impact on scientific productivity by allowing the individual to gain access to a better research environment. This is often labeled as moving up the university hierarchy, that is, moving to a university with a higher 'ranking' (Dubois et al. 2014, Fernández-Zubieta et al. 2015a).

In Sweden, universitet and högskolor (see Section 3) provide a natural division for analyzing hierarchical moves. Online Appendix Table A3 illustrates the significance of this distinction, providing the average number of publications for a researcher-year observation by university, ranked by the average number of publications. Eight universitet and two högskolor, the latter ranked nine and ten, are among the top ten performers. From below, among the ten least publishing institutions are eight högskolor, seven ranked at the bottom and one ranked ninth from the bottom. These descriptive statistics are suggestive of the importance of university status for research 
performance, although they do not standardize results by discipline, composition of researchers, and so forth.

\section{INSERT TABLES 4}

In Table 4, we show regression results in which we distinguish among different types of moves. Instead of only one dummy variable that equals 1 when a researcher changes institution, we now introduce four different dummy variables: (i) 'Universitet to universitet,' which equals 1 when a researcher moves from one university to another university; (ii) 'Högskola to högskola,' which equals 1 when a researcher moves from one university college to another university college; (iii) 'Högskola to universitet,' which equals 1 when a researcher moves from a högskola to a universitet; and (iv) 'Universitet to högskola,' which equals 1 when the opposite type of move occurs. The baseline is to remain, that is, not to move. Through this procedure, we can decompose the effect of mobility estimated in Table 2 into different effects that correspond to moves up or down the university hierarchy. The results of the estimation, displayed in Table 4, point unequivocally to the important role of moves among universities as the only type of moves that boost researchers' productivity. Although this kind of move leads to a statistically significant increase of $43 \%$ in publication counts (18\% in the fixed-effects estimates) and to a $63 \%$ increase in citations ( $33 \%$ in the fixed-effects estimates), the other types of moves never lead to an increase in researcher productivity. In the case of moves from one högskola to another högskola, the moves even have a negative effect in terms of publications and citations. The matched sample approach in Online Appendix Table C4 shows very similar results, with only moves among universitet leading to improved publication and citation outputs, thus confirming the robustness of our findings.

\section{Mobility and disciplinary fields}


Another relevant dimension is the role of different disciplinary fields. In Table 5, we display results obtained by running the model in equation (1) separately for researchers in four different disciplinary fields. Our data allow us to identify the discipline of each researcher, distinguishing among social sciences/humanities, engineering and technology, medicine, and the natural sciences. ${ }^{14}$ When we run our models separately by discipline, we find that the positive effect obtained at the aggregate level is confirmed for engineering and technology as well as medicine but only to some extent for the natural sciences. On the contrary, we find no mobility effect among researchers active in the social sciences and the humanities.

\section{INSERT TABLE 5 ABOUT HERE}

We interpret these results considering the different preconditions for research in the various disciplines. For disciplines such as engineering and medicine, the availability of a (highly costly) research infrastructure can make a difference in the overall quality of research performed. Having access to better equipment or larger labs can substantially increase the chances of achieving better research outcomes in engineering as well as in medicine. However, this is not necessarily the case for research in the humanities and the social sciences, in which most research is conducted without the need for costly investment. It is likely, then, that when researchers in the hard sciences move, they tend to move to academic environments with better endowments in terms of research infrastructure, which complements and augments their research productivity. In the social sciences

\footnotetext{
${ }^{14}$ The disciplinary fields correspond to the first-digit level in the Organization for Economic Cooperation and Development's Field of Science and Technology (FOS) Classification in the Frascati Manual. Because all research in the agricultural and veterinary sciences is confined to the Swedish University of Agricultural Sciences, for which we lack information, this field is excluded from the analysis.
} 
and the humanities, however, moves may more frequently be related to other motives that are less directly linked to productivity.

\section{Conclusion}

In this paper, we investigate the effect of the mobility of researchers on their individual quantity and quality of scientific output. The existing literature argues that mobility might increase academics' individual productivity if it improves research opportunities. This can be the case if a move takes the researcher to a more research-intensive environment or to a position related to an increase in publishing/citations during the life-cycle of a researcher. We also note that productive researchers are more likely to be mobile. In other words, the outcome of interest is also a selection into treatment. To deal with these issues, we employ a weighting technique (IPTCW) that counteracts endogeneity in moves. In robustness checks, we use nonparametric matching techniques to create a sample of similar scientists who do and do not move.

In our preferred specifications, the estimated gain following a move is $29 \%$ in the publishing rate and $50 \%$ in the citation rate. Estimations including both leading and lagged effects suggest that they are not short-term effects, as they last up to seven years after a move. Moreover, the results are not driven mainly by individuals who are promoted at the same time as a move, suggesting that mobility per se explains a large part of productivity increases. We also find that the positive effect of mobility on both publications and citations is only due to moves among universitet, as opposed to other types of moves involving more teaching-intense academic institutions, such as högskolor. Finally, the results point to a stronger effect of mobility for researchers active in engineering and technology and to a lesser extent in medicine and the natural sciences, while no effect is found among researchers in the social sciences and the humanities.

We can draw some conclusions from our empirical findings. Our estimation approaches have taken great care to net out selection effects, because we cannot rule out their existence. Still, the 
gains to mobility for individuals who move are not negligible. Considering that fewer opportunities for mobility exist in Sweden than in larger countries (and therefore mobility is rare), policy makers should consider introducing tools to stimulate interuniversity mobility. This would encourage individuals on the margin (who probably would not move otherwise) to move, when individual net gains from mobility are high. One way of doing this would be to help cover moving costs. Typically, such costs can be social, such as whether a spouse or partner will be able to find a suitable job in the destination region, as well as financial, including the cost of finding housing or child care. Because universities in the Swedish system are becoming increasingly autonomous, these are some areas in which higher freedom for universities to cover social costs may yield high social returns.

Interestingly, our results also suggest considerable sorting effects in the university system: more research-intensive departments (in this context, a universitet) will both hire better researchers and get a bigger 'bang for their buck' in terms of publication by their hires. At the same time, they indicate that moving to a högskola is not a very strategic decision for researchers who want to pursue a research-based career, which does not support the attractiveness of these academic institutions. Finally, the results generally suggest that the publication rate of individuals is closely tied to research budgets and to the time allocated by individuals between teaching and research. It would therefore be interesting to better understand the differential access to research resources that affects publication rates at universities and university colleges (Ejermo and Källström 2016). Another avenue of future research is related to whether mobility helps researchers to expand their network of colleagues who cite them and increase the number of potential co-authors (Ductor 2015). 


\section{References}

AZOULAY, P., DING, W. and STUART, T. (2009). 'The impact of academic patenting on the rate, quality and direction of (public) research output', The Journal of Industrial Economics, Vol. 57, pp. 637-676.

AZOULAY, P., GANGULI, I. and GRAFF ZIVIN, J. S. (2016). The mobility of elite life scientists: professional and personal determinants, NBER Working Paper 21995.

AZOULAY, P., ZIVIN, J. S. G. and SAMPAT, B. N. (2011). 'The Diffusion of Scientific Knowledge across Time and Space: Evidence from Professional Transitions for the Superstars of Medicine', The Rate and Direction of Inventive Activity Revisited. University of Chicago Press, pp. 107-155.

BOLLI, T. and SCHLÄPFER, J. (2015). 'Job mobility, peer effects, and research productivity in economics', Scientometrics, Vol. 104, pp. 629-650.

BUENSTORF, G. (2009). 'Is commercialization good or bad for science? Individual-level evidence from the Max Planck Society', Research Policy, Vol. 38, pp. 281-292.

BÄKER, A. (2015). 'Non-tenured post-doctoral researchers' job mobility and research output: An analysis of the role of research discipline, department size, and coauthors', Research Policy, Vol. 44, pp. 634-650.

CAMERON, A. C. and TRIVEDI, P. K. (2010) Microeconometrics using stata, Stata press College Station, TX.

CRUZ-CASTRO, L. and SANZ-MENÉNDEZ, L. (2010). 'Mobility versus job stability: Assessing tenure and productivity outcomes', Research Policy, Vol. 39, pp. 27-38.

DI LORENZO, F. and TARTARI, V. Should I Stay Or Should I Go? How Mobility Explains Individual Scientific Performance, Paper Presented at the Academy of Management Proceedings, 2014, Academy of Management. 
DUBOIS, P., ROCHET, J.-C. and SCHLENKER, J.-M. (2014). 'Productivity and mobility in academic research: Evidence from mathematicians', Scientometrics, Vol. 98, pp. 16691701.

DUCTOR, L. (2015). 'Does Co-authorship Lead to Higher Academic Productivity?', Oxford Bulletin of Economics and Statistics, Vol. 77, pp. 385-407.

EJERMO, O., ALDER, C., FASSIO, C. and KÄLLSTRÖM, J. (2016). Publications of Academic Researchers in Sweden (PARIS), CIRCLE, Lund University, http://paris.circle.lu.se/.

EJERMO, O. and KÄLLSTRÖM, J. (2016). 'What is the causal effect of R\&D on patenting activity in a "professor's privilege" country? Evidence from Sweden', Small Business Economics, Vol. 47, pp. 677-694.

EUROPEAN COMMISSION (2012). 'Excellence, Equality and Entrepreneurialism Building Sustainable Research Careers in the European Research Area', Report of the Expert Group on the Research Profession. European Commission, Directorate General for Research and Innovation, Brussels.

FERNÁNDEZ-ZUBIETA, A., GEUNA, A. and LAWSON, C. (2015a). 'Productivity pay-offs from academic mobility: should I stay or should I go?', Industrial and Corporate Change. FERNÁNDEZ-ZUBIETA, A., GEUNA, A. and LAWSON, C. (2015b). What do We Know of the Mobility of Research Scientists and of its Impact on Scientific Production, LEI\&BRICK Working Paper 22/15.

FORAY, D. and LISSONI, F. (2010). 'Chapter 6 - University Research and Public-Private Interaction', in BRONWYN H H and NATHAN R (eds.), Handbook of the Economics of Innovation. North-Holland, pp. 275-314.

FRANZONI, C., SCELLATO, G. and STEPHAN, P. (2014). 'The mover's advantage: The superior performance of migrant scientists', Economics letters, Vol. 122, pp. 89-93. 
HALEVI, G., MOED, H. F. and BAR-ILAN, J. (2016). 'Researchers' Mobility, Productivity and Impact: Case of Top Producing Authors in Seven Disciplines', Publishing Research Quarterly, Vol. 32, pp. 22-37.

HOISL, K. (2007). 'Tracing mobile inventors-The causality between inventor mobility and inventor productivity', Research Policy, Vol. 36, pp. 619-636.

HORTA, H., VELOSO, F. M. and GREDIAGA, R. (2010). 'Navel Gazing: Academic Inbreeding and Scientific Productivity', Management Science, Vol. 56, pp. 414-429.

MORICHIKA, N. and SHIBAYAMA, S. (2015). 'Impact of inbreeding on scientific productivity: A case study of a Japanese university department', Research Evaluation, Vol. 24, pp. 146157.

NISTICÒ, R. (2018). 'The Effect of PhD Funding on Postdegree Research Career and Publication Productivity', Oxford Bulletin of Economics and Statistics, pp. n/a-n/a.

OECD (2008) The global competition for talent: Mobility of the highly skilled, OECD Paris.

ROBINS, J. M. (2000). 'Marginal structural models versus structural nested models as tools for causal inference', Statistical models in epidemiology, the environment, and clinical trials. Springer, pp. 95-133.

SABATIER, M. (2012). 'Does productivity decline after promotion? The case of French Academia', Oxford Bulletin of Economics and Statistics, Vol. 74, pp. 886-902.

SCB (2017). 'Andel av total arbetstid för anställda vid universitet och högskolor efter kön, lärosäte, arbetsuppgifter och vartannat år', Available from:

http://www.statistikdatabasen.scb.se/pxweb/sv/ssd/START UF UF0304 UF0304B/U oHIndArsvRelLaro/table/tableViewLayout1/?rxid=561eb25b-5bd4-4075-b2fe-

\section{$\underline{6197067 \mathrm{~d} 78 \mathrm{c} 0 .}$.}


SHANGHAI JIAO TONG UNIVERSITY (2017). 'Academic Ranking of World Universities', Available from: http://www.shanghairanking.com.

STEPHAN, P. E. (2012) How economics shapes science, Harvard University Press Cambridge, MA.

TIMES HIGHER EDUCATION (2018). 'World University Rankings', Available from: www.timeshighereducation.com.

WOOLDRIDGE, J. M. (1999). 'Distribution-free estimation of some nonlinear panel data models', Journal of econometrics, Vol. 90, pp. 77-97.

ZUCKER, L., DARBY, M. R. and TORERO, M. (2002). 'Labor Mobility from Academe to Commerce', Journal of Labor Economics, Vol. 20, pp. 629-660. 
TABLE 1

Descriptive statistics

\begin{tabular}{|c|c|c|c|c|c|c|c|c|c|c|c|}
\hline & \multirow[b]{2}{*}{ mean } & \multicolumn{4}{|c|}{ Movers $(N=1,270)$} & \multicolumn{5}{|c|}{ Stayers $(N=20,551)$} & \multirow[b]{2}{*}{ Diff in mean } \\
\hline & & median & $s d$ & $\min$ & $\max$ & mean & median & $s d$ & $\min$ & $\max$ & \\
\hline No. of publications & 1.74 & 1 & 2.85 & 0 & 34 & 1.20 & 0 & 2.40 & 0 & 50 & $0.53 * * *$ \\
\hline No. of citations & 10.02 & 2 & 36.59 & 0 & 746 & 6.97 & 0 & 25.94 & 0 & 944 & $3.05 * * *$ \\
\hline Cum. no. of publications & 10.32 & 4 & 18.39 & 0 & 192 & 7.59 & 1 & 18.91 & 0 & 452 & $2.73 * * *$ \\
\hline Cum. no. of citations & 58.80 & 9 & 168.56 & 0 & 2626 & 44.56 & 1 & 174.80 & 0 & 7818 & $14.24 * * *$ \\
\hline Age & 43.49 & 42 & 9.89 & 25 & 73 & 43.47 & 42 & 12.56 & 18 & 84 & 0.02 \\
\hline Years since degree & 7.84 & 6 & 7.09 & 0 & 37 & 9.53 & 6 & 9.97 & 0 & 50 & $-1.69 * * *$ \\
\hline Male & 0.56 & 1 & 0.49 & 0 & 1 & 0.59 & 1 & 0.49 & 0 & 1 & -0.02 \\
\hline Children & 0.85 & 1 & 0.95 & 0 & 5 & 0.67 & 0 & 0.92 & 0 & 8 & $0.18 * * *$ \\
\hline Married/Cohabitating & 0.65 & 1 & 0.43 & 0 & 1 & 0.58 & 1 & 0.47 & 0 & 1 & $0.06 * * *$ \\
\hline Full Professors & 0.18 & 0 & 0.33 & 0 & 1 & 0.15 & 0 & 0.33 & 0 & 1 & $0.03 * * *$ \\
\hline Associate Professors & 0.35 & 0 & 0.40 & 0 & 1 & 0.27 & 0 & 0.41 & 0 & 1 & $0.08 * * *$ \\
\hline Postdocs & 0.03 & 0 & 0.12 & 0 & 1 & 0.09 & 0 & 0.28 & 0 & 1 & $-0.06 * * *$ \\
\hline Guest researchers & 0.33 & 0 & 0.39 & 0 & 1 & 0.42 & 0 & 0.46 & 0 & 1 & $-0.09 * * *$ \\
\hline 'Other' researchers & 0.11 & 0 & 0.22 & 0 & 1 & 0.07 & 0 & 0.22 & 0 & 1 & $0.04 * * *$ \\
\hline
\end{tabular}

Note: Each individual is averaged as one observation in the table. PhD students are excluded. The category 'other' research staff mainly consists of PhDs working in academia and doing research but who lack an academic position. 
TABLE 2

Main Effect of Mobility

\begin{tabular}{lcccc}
\hline & $\begin{array}{c}(1) \\
\text { Publications } \\
\text { IPTC weights }\end{array}$ & $\begin{array}{c}\text { Publications } \\
\text { Fixed effects }\end{array}$ & $\begin{array}{c}\text { (3) } \\
\text { Citations } \\
\text { IPTC weights }\end{array}$ & $\begin{array}{c}\text { Citations } \\
\text { Fixed effects }\end{array}$ \\
\hline Variables & & & & \\
PostMob & $0.295^{* * *}$ & $0.171^{* * *}$ & $0.501 * * *$ & $0.295^{* *}$ \\
& $(0.0846)$ & $(0.0440)$ & $(0.160)$ & $(0.126)$ \\
Observations & & & & \\
Number of individuals & 69,902 & 71,945 & 69,902 & 63,583 \\
Individual fixed effects (FE) & 14,087 & 10,326 & 14,087 & 9,054 \\
Scientific Field FE & No & Yes & No & Yes \\
Year FE & Yes & No & Yes & No \\
Estimation method & Yes & Yes & Yes & Yes \\
\multicolumn{2}{c}{ Note: Robust standard errors clustered at the individual level in parenthesis. ${ }^{* * *} \mathrm{p}<0.01,{ }^{* *} \mathrm{p}<0.05, * \mathrm{p}<0.1}$.
\end{tabular}

\section{FIGURE 1}

Dynamics of treatment: Poisson with IPTC weights

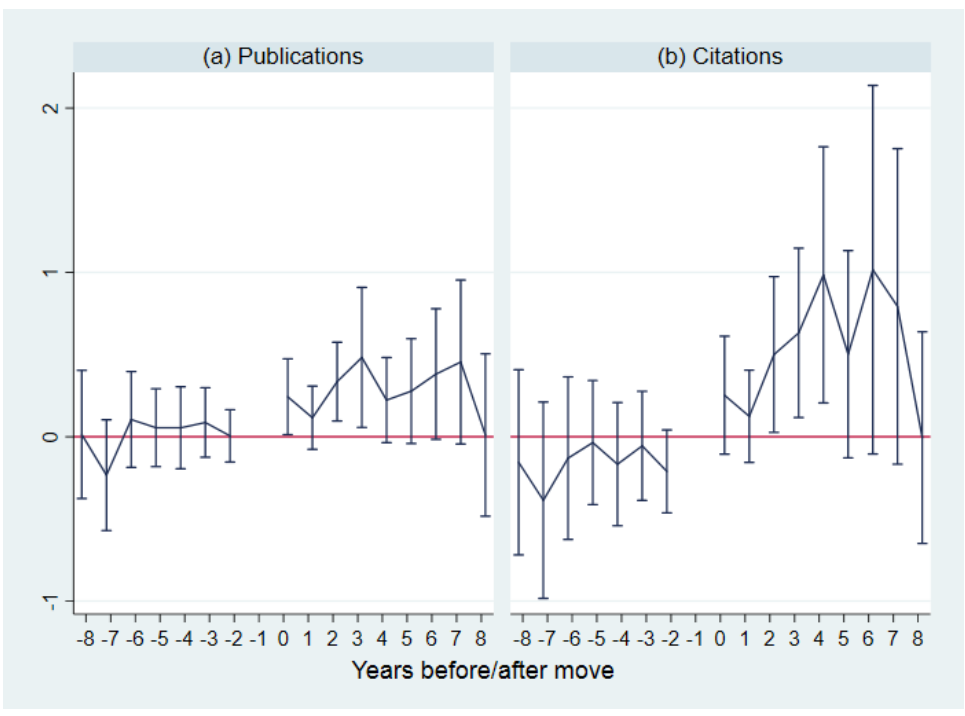

Note: This figure plots point estimates for leading and lagging indicators for mobility. The omitted category is one year prior to the move. All specifications include individual- and year-fixed effects as well as controls for children, cohabitating, age squared, experience, and experience squared. Vertical bars correspond to 95 confidence intervals with robust standard errors clustered at the individual level. 
TABLE 3

Effect of Career Transitions and Moving

\begin{tabular}{|c|c|c|c|c|}
\hline Variables & $\begin{array}{c}\text { (1) } \\
\text { Publications } \\
\text { IPTC weights }\end{array}$ & $\begin{array}{c}\text { (2) } \\
\text { Publications } \\
\text { Fixed effects }\end{array}$ & $\begin{array}{c}\text { (3) } \\
\text { Citations } \\
\text { IPTC weights }\end{array}$ & $\begin{array}{c}\text { (4) } \\
\text { Citations } \\
\text { Fixed effects }\end{array}$ \\
\hline PostMob \& No & $0.302 * * *$ & $0.195 * * *$ & $0.401 *$ & $0.290^{* *}$ \\
\hline & $(0.115)$ & $(0.0712)$ & $(0.218)$ & $(0.140)$ \\
\hline PostMob \& Promotion & $\begin{array}{c}0.478^{* * *} \\
(0.167)\end{array}$ & $\begin{array}{c}0.236^{* * *} \\
(0.0540)\end{array}$ & $\begin{array}{c}0.738^{* *} \\
(0.322)\end{array}$ & $\begin{array}{l}0.267^{*} \\
(0.145)\end{array}$ \\
\hline Stay \& Promotion & $\begin{array}{c}0.307 * * * \\
(0.0539)\end{array}$ & $\begin{array}{c}0.117 * * * \\
(0.0205)\end{array}$ & $\begin{array}{c}0.259^{* *} \\
(0.103)\end{array}$ & $\begin{array}{c}0.150 * * * \\
(0.0541)\end{array}$ \\
\hline PostMob \& Demotion & $\begin{array}{c}0.261 \\
(0.179)\end{array}$ & $\begin{array}{c}0.175 \\
(0.122)\end{array}$ & $\begin{array}{c}0.632 \\
(0.411)\end{array}$ & $\begin{array}{c}0.503 \\
(0.429)\end{array}$ \\
\hline Stay \& Demotion & $\begin{array}{c}0.111 \\
(0.0796)\end{array}$ & $\begin{array}{c}0.0522 \\
(0.0379)\end{array}$ & $\begin{array}{l}0.00315 \\
(0.101)\end{array}$ & $\begin{array}{c}-0.0292 \\
(0.0737)\end{array}$ \\
\hline Observations & 69,902 & 71,945 & 69,902 & 63,583 \\
\hline Number of individuals & 14,087 & 10,326 & 14,087 & 9,054 \\
\hline Time-varying controls & Yes & Yes & Yes & Yes \\
\hline Time-fixed controls & Yes & No & Yes & No \\
\hline Individual FE & No & Yes & No & Yes \\
\hline Estimation method & Poisson & Poisson & Poisson & Poisson \\
\hline
\end{tabular}

TABLE 5

Effect of Mobility and University Hierarchies

\begin{tabular}{lcccc}
\hline & $\begin{array}{c}(1) \\
\text { Publications } \\
\text { IPTC weights }\end{array}$ & $\begin{array}{c}\text { Publications } \\
\text { Fixed effects }\end{array}$ & $\begin{array}{c}\text { (3) } \\
\text { Citations } \\
\text { IPTC weights }\end{array}$ & $\begin{array}{c}\text { Citations } \\
\text { Fixed effects }\end{array}$ \\
\hline & & & & \\
Variables & $0.432^{* * *}$ & $0.182^{* * *}$ & $0.631^{* * *}$ & $0.335^{* *}$ \\
'Universitet' to 'universitet' & $(0.0950)$ & $(0.0523)$ & $(0.165)$ & $(0.140)$ \\
& $-0.848^{* * *}$ & 0.189 & $-1.889^{* * *}$ & -0.168 \\
'Högskola' to 'högskola' & $(0.235)$ & $(0.135)$ & $(0.371)$ & $(0.258)$ \\
& -0.233 & 0.157 & $-0.628^{*}$ & -0.0140 \\
'Högskola' to Universitet' & $(0.146)$ & $(0.101)$ & $(0.353)$ & $(0.222)$ \\
& -0.265 & $0.167^{*}$ & -0.570 & 0.113 \\
Universitet' to högskola' & $(0.232)$ & $(0.0950)$ & $(0.398)$ & $(0.274)$ \\
& & & & \\
Observations & 69,902 & 71,945 & 69,902 & 63,583 \\
Time-varying controls & Yes & Yes & Yes & Yes \\
Number of individuals & 14,087 & 10,326 & 14,087 & 9,054 \\
Time-fixed controls & Yes & No & Yes & No \\
Individual FE & No & Yes & No & Yes \\
Estimation method & Poisson & Poisson & Poisson & Poisson \\
\hline \multicolumn{2}{c}{ Note: Robust standard errors clustered at the individual level in parenthesis. *** p<0.01, ** p<0.05, $* 0.1}$.
\end{tabular}

TABLE 6 
Effect of Mobility within Disciplines

\begin{tabular}{|c|c|c|c|c|}
\hline Variables & $\begin{array}{c}\text { (1) } \\
\text { Publications } \\
\text { IPTC weights }\end{array}$ & $\begin{array}{c}\text { (2) } \\
\text { Publications } \\
\text { Fixed effects }\end{array}$ & $\begin{array}{c}\text { (3) } \\
\text { Citations } \\
\text { IPTC weights }\end{array}$ & $\begin{array}{c}\text { (4) } \\
\text { Citations } \\
\text { Fixed effects }\end{array}$ \\
\hline Social sciences/Humanities & $\begin{array}{c}0.286 \\
(0.215)\end{array}$ & $\begin{array}{c}-0.0682 \\
(0.0943)\end{array}$ & $\begin{array}{c}0.373 \\
(0.423)\end{array}$ & $\begin{array}{l}0.0561 \\
(0.272)\end{array}$ \\
\hline Observations & 24,118 & 17,604 & 24,118 & 12,598 \\
\hline Number of individuals & 4,942 & 2,307 & 4,942 & 1,622 \\
\hline Medicine & $\begin{array}{c}0.264 * * \\
(0.127)\end{array}$ & $\begin{array}{c}0.268 * * * \\
(0.0749)\end{array}$ & $\begin{array}{c}0.268 \\
(0.200)\end{array}$ & $\begin{array}{c}0.281 * * \\
(0.122)\end{array}$ \\
\hline Observations & 17,851 & 22,142 & 17,851 & 21,543 \\
\hline Number of individuals & 3,867 & 3,555 & 3,867 & 3,430 \\
\hline Natural sciences & $\begin{array}{c}0.327 * * * \\
(0.127)\end{array}$ & $\begin{array}{l}-0.0327 \\
(0.100)\end{array}$ & $\begin{array}{l}0.0809 \\
(0.194)\end{array}$ & $\begin{array}{l}-0.114 \\
(0.163)\end{array}$ \\
\hline Observations & 10,136 & 11,554 & 10,136 & 10,890 \\
\hline Number of individuals & 2,015 & 1,664 & 2,015 & 1,548 \\
\hline Engineering/Technology & $\begin{array}{c}0.378^{* *} \\
(0.181)\end{array}$ & $\begin{array}{c}0.211^{* * *} \\
(0.0736)\end{array}$ & $\begin{array}{c}1.361 * * * \\
(0.367)\end{array}$ & $\begin{array}{c}0.402 \\
(0.353)\end{array}$ \\
\hline Observations & 17,797 & 20,504 & 17,797 & 18,399 \\
\hline Number of individuals & 3,409 & 2,875 & 3,409 & 2,520 \\
\hline Time-varying controls & Yes & Yes & Yes & Yes \\
\hline Time-fixed controls & Yes & No & Yes & No \\
\hline Individual FE & No & Yes & No & Yes \\
\hline Estimation method & Poisson & Poisson & Poisson & Poisson \\
\hline
\end{tabular}




\section{Appendix A: Tables and Graphs}

APPENDIX TABLE A1

Years covered by staff lists from responding universities

\begin{tabular}{|c|c|c|c|c|c|c|c|c|c|c|c|c|c|c|c|c|c|c|c|c|c|c|c|c|c|}
\hline Years & BTH & $\mathrm{CTH}$ & $\boldsymbol{G U}$ & $H B$ & $H D A$ & $H H$ & $H J$ & $H K R$ & $H S$ & $H V$ & $\boldsymbol{K A} \boldsymbol{A}$ & KI & KTH & $L I U$ & $L N U$ & $L T U$ & $L U$ & $M A H$ & $M D H$ & $M I U$ & $O R U$ & $\mathrm{SH}$ & $S U$ & $\boldsymbol{U M U}$ & $\boldsymbol{U} \boldsymbol{U}$ \\
\hline 1983 & & & & & & & & & & & & & & & & & $\mathbf{X}$ & & & & & & & & \\
\hline 1984 & & & & & & & & & & & & & & & & & $\mathbf{X}$ & & & & & & & & \\
\hline 1985 & & & & & & & & & & & & & & & & & $\mathbf{X}$ & & & & & & & & \\
\hline 1986 & & & & & & & & & & & & & & & & & $\mathbf{X}$ & & & & & & & & \\
\hline 1987 & & & & & & & & & & & & & & & & & $\mathbf{X}$ & & & & & & & & \\
\hline 1988 & & & & & & & & & & & & & & & & & $\mathbf{X}$ & & & & & & & & \\
\hline 1989 & & & & & & & & & & & & & & & & & $\mathbf{X}$ & & & & & & & & \\
\hline 1990 & & & $\mathbf{X}$ & & & & & & & & & & & & & & $\mathbf{X}$ & & & $\mathbf{X}$ & $X$ & & & $\mathbf{X}$ & \\
\hline 1991 & & & $\mathbf{X}$ & & & & & & & & & & & & & & $\mathbf{X}$ & & & $\mathbf{X}$ & $X$ & & & $\mathbf{X}$ & \\
\hline 1992 & & & $\mathbf{X}$ & & & & & & & & & & & & & & $\mathbf{X}$ & & & $\mathbf{X}$ & X & & & $\mathbf{X}$ & \\
\hline 1993 & & & $\mathbf{X}$ & & $X$ & & & & & & & & & & & & $\mathbf{X}$ & & & $\mathbf{X}$ & X & & & $\mathbf{X}$ & \\
\hline 1994 & & & $\mathbf{X}$ & & $X$ & & & & & & & & & & $\mathbf{X}$ & & $\mathbf{X}$ & & & $\mathbf{X}$ & X & & & $\mathbf{X}$ & $\mathbf{X}$ \\
\hline 1995 & & & $\mathbf{X}$ & & $X$ & & & X & & & & & & & $\mathbf{X}$ & & $\mathbf{X}$ & & & $\mathbf{X}$ & $X$ & & & $\mathbf{X}$ & $\mathbf{X}$ \\
\hline 1996 & & & $\mathbf{X}$ & & $X$ & & & $X$ & & & & & & & $\mathbf{X}$ & & $\mathbf{X}$ & & & $\mathbf{X}$ & $X$ & & & $\mathbf{X}$ & $\mathbf{X}$ \\
\hline 1997 & & & $\mathbf{X}$ & & $X$ & & X & $X$ & & & $\mathbf{X}$ & & & & $\mathbf{X}$ & & $\mathbf{X}$ & & & $\mathbf{X}$ & $X$ & X & & $\mathbf{X}$ & $\mathbf{X}$ \\
\hline 1998 & X & $\mathbf{X}$ & $\mathbf{X}$ & & X & & X & $X$ & & & $\mathbf{X}$ & & & & $\mathbf{X}$ & & $\mathbf{X}$ & X & & $\mathbf{X}$ & X & $X$ & & $\mathbf{X}$ & $\mathbf{X}$ \\
\hline 1999 & $X$ & $\mathbf{X}$ & $\mathbf{X}$ & & $X$ & & $\mathrm{X}$ & $\mathrm{X}$ & & & $\mathbf{X}$ & & $\mathbf{X}$ & & $\mathbf{X}$ & & $\mathbf{X}$ & $X$ & & $\mathbf{X}$ & $X$ & $X$ & & $\mathbf{X}$ & $\mathbf{X}$ \\
\hline 2000 & $X$ & $\mathbf{X}$ & $\mathbf{X}$ & & $X$ & & $\mathrm{X}$ & $X$ & & & $\mathbf{X}$ & & $\mathbf{X}$ & & $\mathbf{X}$ & & $\mathbf{X}$ & $\mathrm{X}$ & & $\mathbf{X}$ & $X$ & $X$ & & $\mathbf{X}$ & $\mathbf{X}$ \\
\hline 2001 & $X$ & $\mathbf{X}$ & $\mathbf{X}$ & & $\mathrm{X}$ & & $\mathrm{X}$ & $\mathrm{X}$ & & & $\mathbf{X}$ & $\mathbf{X}$ & $\mathbf{X}$ & $\mathbf{X}$ & $\mathbf{X}$ & & $\mathbf{X}$ & $\mathrm{X}$ & $X$ & $\mathbf{X}$ & $X$ & $\mathrm{X}$ & & $\mathbf{X}$ & $\mathbf{X}$ \\
\hline 2002 & $\mathrm{X}$ & $\mathbf{X}$ & $\mathbf{X}$ & & $X$ & & $\mathrm{X}$ & $X$ & X & X & $\mathbf{X}$ & $\mathbf{X}$ & $\mathbf{X}$ & $\mathbf{X}$ & $\mathbf{X}$ & $\mathbf{X}$ & $\mathbf{X}$ & $\mathrm{X}$ & $X$ & $\mathbf{X}$ & $X$ & $X$ & & $\mathbf{X}$ & $\mathbf{X}$ \\
\hline 2003 & $X$ & $\mathbf{X}$ & $\mathbf{X}$ & & $X$ & X & $\mathrm{X}$ & $X$ & $X$ & $X$ & $\mathbf{X}$ & $\mathbf{X}$ & $\mathbf{X}$ & $\mathbf{X}$ & $\mathbf{X}$ & $\mathbf{X}$ & $\mathbf{X}$ & $X$ & $X$ & $\mathbf{X}$ & $X$ & $X$ & & $\mathbf{X}$ & $\mathbf{X}$ \\
\hline 2004 & $X$ & $\mathbf{X}$ & $\mathbf{X}$ & & $X$ & $X$ & $\mathrm{X}$ & $X$ & $X$ & $X$ & $\mathbf{X}$ & $\mathbf{X}$ & $\mathbf{X}$ & $\mathbf{X}$ & $\mathbf{X}$ & $\mathbf{X}$ & $\mathbf{X}$ & $X$ & $X$ & $\mathbf{X}$ & $X$ & $X$ & $\mathbf{X}$ & $\mathbf{X}$ & $\mathbf{X}$ \\
\hline 2005 & $X$ & $\mathbf{X}$ & $\mathbf{X}$ & & $X$ & $\mathrm{X}$ & $\mathrm{X}$ & $X$ & $X$ & $X$ & $\mathbf{X}$ & $\mathbf{X}$ & $\mathbf{X}$ & $\mathbf{X}$ & $\mathbf{X}$ & $\mathbf{X}$ & $\mathbf{X}$ & $X$ & $X$ & $\mathbf{X}$ & $X$ & $X$ & $\mathbf{X}$ & $\mathbf{X}$ & $\mathbf{X}$ \\
\hline 2006 & $X$ & $\mathbf{X}$ & $\mathbf{X}$ & & X & X & $\mathrm{X}$ & $X$ & X & X & $\mathbf{X}$ & $\mathbf{X}$ & $\mathbf{X}$ & $\mathbf{X}$ & $\mathbf{X}$ & $\mathbf{X}$ & $\mathbf{X}$ & X & X & $\mathbf{X}$ & X & X & $\mathbf{X}$ & $\mathbf{X}$ & $\mathbf{X}$ \\
\hline 2007 & X & $\mathbf{X}$ & $\mathbf{X}$ & & X & $\mathrm{X}$ & $\mathrm{X}$ & X & X & X & $\mathbf{X}$ & $\mathbf{X}$ & $\mathbf{X}$ & $\mathbf{X}$ & $\mathbf{X}$ & $\mathbf{X}$ & $\mathbf{X}$ & X & X & $\mathbf{X}$ & X & X & $\mathbf{X}$ & $\mathbf{X}$ & $\mathbf{X}$ \\
\hline 2008 & $X$ & $\mathbf{X}$ & $\mathbf{X}$ & & X & X & $\mathrm{X}$ & X & X & X & $\mathbf{X}$ & $\mathbf{X}$ & $\mathbf{X}$ & $\mathbf{X}$ & $\mathbf{X}$ & $\mathbf{X}$ & $\mathbf{X}$ & X & X & $\mathbf{X}$ & X & X & $\mathbf{X}$ & $\mathbf{X}$ & $\mathbf{X}$ \\
\hline 2009 & $X$ & $\mathbf{X}$ & $\mathbf{X}$ & & X & X & X & $X$ & X & X & $\mathbf{X}$ & $\mathbf{X}$ & $\mathbf{X}$ & $\mathbf{X}$ & $\mathbf{X}$ & $\mathbf{X}$ & $\mathbf{X}$ & $X$ & X & $\mathbf{X}$ & X & $X$ & $\mathbf{X}$ & $\mathbf{X}$ & $\mathbf{X}$ \\
\hline 2010 & X & $\mathbf{X}$ & $\mathbf{X}$ & & $X$ & X & X & $X$ & X & X & $\mathbf{X}$ & $\mathbf{X}$ & $\mathbf{X}$ & $\mathbf{X}$ & $\mathbf{X}$ & $\mathbf{X}$ & $\mathbf{X}$ & X & X & $\mathbf{X}$ & X & $X$ & $\mathbf{X}$ & $\mathbf{X}$ & $\mathbf{X}$ \\
\hline 2011 & X & $\mathbf{X}$ & $\mathbf{X}$ & & $X$ & X & X & $X$ & X & X & $\mathbf{X}$ & $\mathbf{X}$ & $\mathbf{X}$ & $\mathbf{X}$ & $\mathbf{X}$ & $\mathbf{X}$ & $\mathbf{X}$ & X & X & $\mathbf{X}$ & X & $X$ & $\mathbf{X}$ & $\mathbf{X}$ & $\mathbf{X}$ \\
\hline 2012 & $X$ & $\mathbf{X}$ & $\mathbf{X}$ & & $X$ & $X$ & X & $X$ & X & $X$ & $\mathbf{X}$ & $\mathbf{X}$ & $\mathbf{X}$ & $\mathbf{X}$ & $\mathbf{X}$ & $\mathbf{X}$ & $\mathbf{X}$ & X & X & $\mathbf{X}$ & X & $X$ & $\mathbf{X}$ & $\mathbf{X}$ & $\mathbf{X}$ \\
\hline $\begin{array}{l}2013 \\
2014\end{array}$ & $\mathrm{X}$ & $\mathbf{X}$ & $\mathbf{X}$ & $X$ & $\mathrm{X}$ & $\mathrm{X}$ & $\mathrm{X}$ & $\mathrm{X}$ & $\mathrm{X}$ & $\mathrm{X}$ & $\mathbf{X}$ & $\mathbf{X}$ & $\mathbf{X}$ & $\mathbf{X}$ & $\mathbf{X}$ & $\mathbf{X}$ & $\begin{array}{l}\mathbf{X} \\
\mathbf{X}\end{array}$ & $\mathrm{X}$ & $\mathrm{X}$ & $\mathbf{X}$ & $\begin{array}{l}X \\
X\end{array}$ & $\mathrm{X}$ & $\mathbf{X}$ & $\mathbf{X}$ & $\mathbf{X}$ \\
\hline
\end{tabular}

Note: $\mathrm{BTH}=$ Blekinge Institute of Technology, $\mathrm{CTH}=$ Chalmers University of Technology, $\mathrm{GU}=$ Gothenburg University, HB=University of Borås, HDA=Dalarna University, $\mathrm{HH}=\mathrm{Halmstad}$
University, $\mathrm{HJ}=\mathrm{J}$ Önköping Technology, LIU=Linköping University, LNU=Linnaeus University, LTU=Luleå Technical University, MAH=Malmö University, MDH=Mälardalen University, MIU=Mid Sweden University,

$\mathrm{ORU}=$ Örebro University, SH=Södertörn University, SU=Stockholm University, UMU=Umeå University, UU=Uppsala University. Universities are marked in boldface. Preferred time period of analysis between the dotted lines. 


\section{APPENDIX TABLE A2}

Positional transition probabilities (\%)

\begin{tabular}{|c|c|c|c|c|c|c|c|c|c|c|c|c|c|c|c|c|c|c|}
\hline \multirow{2}{*}{$\begin{array}{l}\text { Position in } t-1 \\
\text { Position in } t\end{array}$} & \multicolumn{3}{|c|}{ Full professor } & \multicolumn{3}{|c|}{ Associate professor } & \multicolumn{3}{|c|}{ Postdoc } & \multicolumn{3}{|c|}{ Guest researchers } & \multicolumn{3}{|c|}{ Other researchers } & \multicolumn{3}{|c|}{ Total } \\
\hline & All & Movers & Stayers & All & Movers & Stayers & All & Movers & Stayers & All & Movers & Stayers & All & Movers & Stayers & All & Movers & Stayers \\
\hline Full professor & 93.0 & 87.8 & 93.5 & 0.1 & 0.4 & 0.0 & 0.0 & 0.0 & 0.0 & 2.5 & 6.7 & 2.2 & 1.2 & 1.3 & 1.2 & 28.2 & 24.8 & 28.5 \\
\hline Associate professor & 5.3 & 8.1 & 5.0 & 93.5 & 88.4 & 94.0 & 4.1 & 7.4 & 3.6 & 6.8 & 20.1 & 5.9 & 2.8 & 6.0 & 2.4 & 40.4 & 39.9 & 40.4 \\
\hline Postdoc & 0.2 & 0.8 & 0.1 & 2.0 & 3.6 & 1.9 & 75.0 & 69.4 & 75.8 & 0.5 & 1.3 & 0.5 & 2.9 & 4.2 & 2.8 & 6.7 & 9.2 & 6.4 \\
\hline Guest researchers & 0.2 & 0.9 & 0.2 & 1.0 & 2.1 & 0.8 & 0.6 & 1.2 & 0.5 & 82.3 & 53.0 & 84.4 & 1.8 & 1.6 & 1.9 & 3.1 & 2.6 & 3.2 \\
\hline Other researchers & 1.3 & 2.4 & 1.2 & 3.5 & 5.4 & 3.3 & 20.3 & 22.0 & 20.1 & 7.8 & 18.8 & 7.0 & 91.3 & 86.9 & 91.7 & 21.7 & 23.5 & 21.5 \\
\hline Total transitions (\%) & 100.0 & 100.0 & 100.0 & 100.0 & 100.0 & 100.0 & 100.0 & 100.0 & 100.0 & 100.0 & 100.0 & 100.0 & 100.0 & 100.0 & 100.0 & 100.0 & 100.0 & 100.0 \\
\hline Total transitions $(\mathrm{N})$ & 24,509 & 2,100 & 22,409 & 33,103 & 3,035 & 30,068 & 5,692 & 732 & 4,960 & 2236 & 149 & 2,087 & 16,428 & 1,591 & 14,837 & 81,968 & 7,607 & 74,361 \\
\hline
\end{tabular}

Note: Numbers in boldface denotes the share of individuals, by category, that do not change position. 
APPENDIX TABLE A3

Average number of publications and citations per year and researcher, by university and university status

$\begin{array}{ccc}\text { University status } & \begin{array}{c}\text { Average number } \\ \text { University name }\end{array} & \begin{array}{c}\text { Average number } \\ \text { (Universitet }=1 / \text { Högskola }=0)\end{array} \\ \text { of publications } & \text { of citations }\end{array}$

\begin{tabular}{llcc}
\hline Karolinska Institute & 1 & 3.05 & 27.42 \\
Royal Institute of Technology & 1 & 2.88 & 10.85 \\
Chalmers University of Technology & 1 & 2.81 & 9.49 \\
Lund University & 1 & 2.33 & 14.82 \\
Uppsala University & 1 & 2.11 & 14.08 \\
Linköping University & 1 & 1.95 & 7.57 \\
Gothenburg University & 1 & 1.58 & 10.57 \\
Luleå University of Technology & 1 & 1.46 & 2.91 \\
Blekinge Institute of Technology & 0 & 1.38 & 1.94 \\
Jönköping University & 0 & 1.36 & 4.25 \\
Stockholm University & 1 & 1.19 & 8.54 \\
Umeå University & 1 & 1.12 & 6.8 \\
Örebro University & 1 & 1.07 & 4.85 \\
University of Borås* & 0 & 1.01 & 3.18 \\
Mid-Sweden University & 1 & 0.95 & 2.22 \\
Karlstad University & 1 & 0.9 & 2.33 \\
Mälardalen University & 0 & 0.88 & 2.38 \\
Linnaeus University & 1 & 0.81 & 2.33 \\
Halmstad University & 0 & 0.74 & 1.45 \\
Malmö University & 0 & 0.71 & 2.15 \\
Kristianstad University & 0 & 0.68 & 2.22 \\
University of Skövde & 0 & 0.68 & 1.23 \\
University College West & 0 & 0.46 & 0.83 \\
Dalarna University College & 0 & 0.45 & 0.85 \\
Södertörn University & 0 & 0.37 & 1.83 \\
\hline & & & \\
\hline
\end{tabular}

* Only observed for one year. 


\section{APPENDIX FIGURE A1}

\section{Dynamics of moving, Poisson fixed effects}

(a) Publications

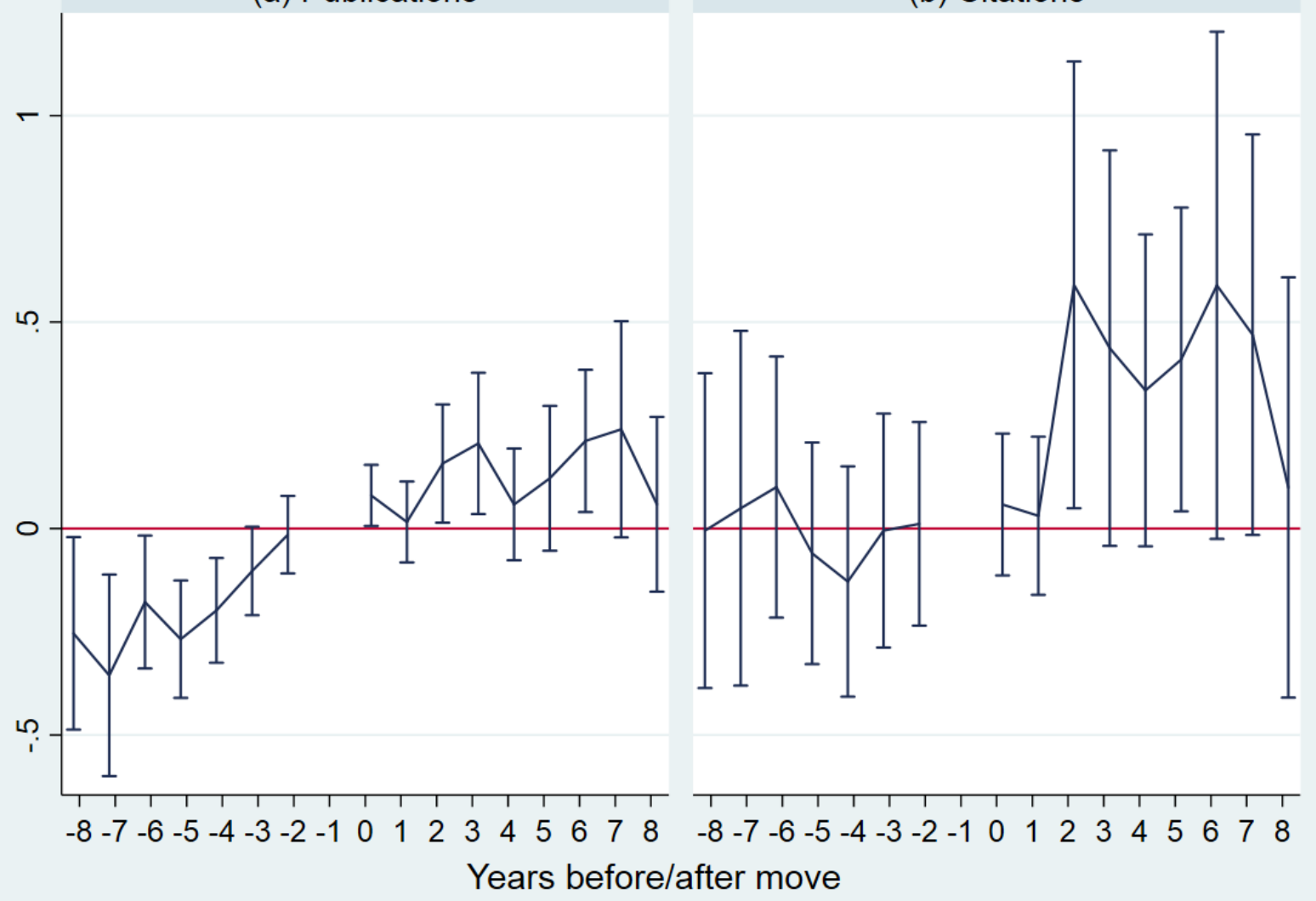

Note: This figure plots point estimates for leading and lagging indicators for mobility. The omitted category is one year prior to the move. All specifications include individual- and year-fixed effects as well as controls for children, cohabitating, age squared, experience, and experience squared. Vertical bars correspond to $95 \%$ confidence intervals with robust standard errors clustered at the individual level. 


\section{Appendix B: Construction of our matched sample}

As an alternative approach, we use an algorithm (coarsened exact matching, CEM) to match mobile researchers with stayers with similar publication trends and other characteristics at the same career stage before the move. This reduces selection problems, in which scientists who are more productive are also more likely to be mobile, with different prospects for mobility at different stages of their career. An advantage of the matched sample approach is that it removes concerns regarding functional form, such as a nonlinear relationship between the dependent and the independent variables (Imbens 2004, Moffitt 2004).

A trade-off exists between finding matches for as many of the treated individuals as possible, which increases the generalizability of our results, against the precision of the match. To obtain high precision in matching, we can increase the number of matching variables, and the exactness of the categories by which we match the individuals, but at the cost of losing matched observations, which reduces generalizability. We use these data to construct our matched sample of 650 mobile researchers and 650 immobile 'twin' researchers implementing the nonparametric matching method coarsened exact matching (CEM) (Blackwell et al. 2009) to create a matched sample, matching one control for each mobile treated individual. In line with previous studies (Azoulay et al. 2010), we match researchers on (a) publication flow in year t-1, (b) cumulative publication stock in $\mathrm{t}-2$, (c) cumulative citation count in $\mathrm{t}-1$, (d) age in $\mathrm{t}-1$, (e) position in $\mathrm{t}-1$, and ( $\mathrm{f}$ ) calendar year in $\mathrm{t}-1$.

Considering that what constitutes normal publication and citation rates varies among disciplines, we coarsen the joint distribution of these variables by discipline (social sciences/humanities, engineering, medicine, or natural sciences), into several strata. The distribution of publication flows is coarsened into four strata (the three bottom quartiles; the 75th to 95th percentiles and above the 95th percentile). The stock of cumulative publications is 
coarsened into eight strata ( 0 to 10 th percentile; 10 th to 25 th percentile; 25 th to 50 th percentile; 50th to 75 th percentile; 75 th to 90 th percentile; 90th to 95th percentile; 95th to 99th percentiles; and above the 99th percentile). Cumulative citations are coarsened into seven strata (the bottom quartile; 25 th to 50 th percentile; 50 th to 75 th percentile; 75 th to 90 th percentile; 90 th to 95 th percentiles; 95th to 99th percentiles; and above the 99th percentile). The distribution of age is coarsened into quartiles, which captures much of life-cycle patterns and is critical to eliminating differences in pretreatment values over time. We exact match on position and on calendar year, rather than coarsen these variables. Exact matching on calendar year is necessary, since otherwise we run the risk that matched publication rates capture, e.g., trends in publication rates, distorting the interpretation.

Using these matching criteria and with the restriction that a treated individual cannot also be a control individual, we match one-to-one without replacement. In cases of ties, CEM randomly chooses one match. Moreover, it is possible for the same individual to be assigned as a control for several treated. In these cases, we randomly select one matched pair. In the end, we find a control researcher for 650 movers. These movers (treated) and stayers (controls) hold the same position in t-1 and share similar career trajectories, the only (measured) difference being that in year $t$ one moves, whereas the other does not. Note that while the matched sample may improve the internal validity, there is a trade-off in terms of external validity.

In Appendix $\mathrm{C}$, we include further details of our matching procedure. Appendix Figure $\mathrm{C} 1$ shows the trend of mean publication and citation rates for treated and control researchers. The graph indicates that the matching procedure reduces pretreatment differences between the treated and the control group in terms of outcomes. It also indicates that researchers who move experience a positive effect from mobility on both publication output and citations, although the graph does not account for other confounding characteristics. Appendix Table $\mathrm{C} 1$ shows the balancing 
properties of the matched sample and verifies that pretreatment characteristics are very similar for treated and controls. Especially important is that for the outcome variables - publications and citations - both the flow and the cumulative sums are very similar. On average, an individual in our matched sample published 1.5-1.6 publications and the publications during that year received 7-8 citations on average within a three-year window.

Unlike the IPTCW method, matched samples can also be combined with a fixed-effect difference-in-differences approach. Still, to the extent that matching does not remove differences in unobservable variation, selection may influence the results. Moreover, by substantially reducing our sample, the matching procedure reduces the generalizability of our results. These reasons make the IPTCW approach preferable, while here we use the matched sample approach as a further robustness analysis.

\section{References}

AZOULAY, P., GRAFF ZIVIN, J. S. and WANG, J. (2010). 'Superstar Extinction', The Quarterly Journal of Economics, Vol. 125, pp. 549-589.

BLACKWELL, M., IACUS, S., KING, G. and PORRO, G. (2009). 'Cem: Coarsened Exact Matching in Stata', Stata Journal, Vol. 9, pp. 524.

IMBENS, G. W. (2004). 'Nonparametric Estimation of Average Treatment Effects under Exogeneity: A Review', Review of Economics and Statistics, Vol. 86, pp. 4-29.

MOFFITT, R. A. (2004). 'Introduction to the Symposium on the Econometrics of Matching', Review of Economics and Statistics, Vol. 86, pp. 1-3. 


\section{Appendix C: Matched sample results}

APPENDIX FIGURE C1

Unconditional mean number of (a) publication and (b) citations trends for treated and control researchers in our matched sample.

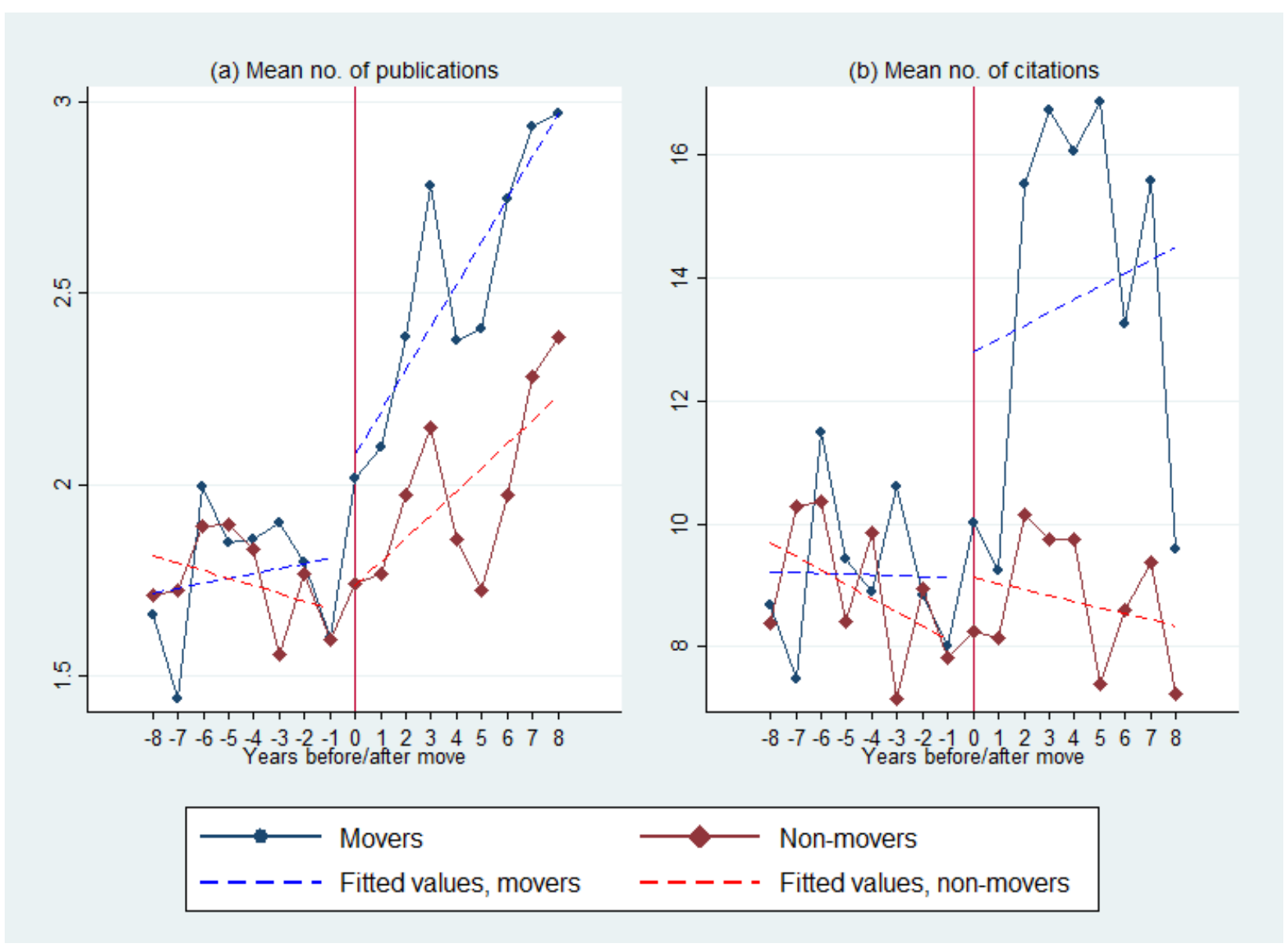




\section{APPENDIX TABLE C}

Descriptive statistics, matched sample

\begin{tabular}{|c|c|c|c|c|c|c|c|c|c|c|c|}
\hline & \multicolumn{5}{|c|}{ Movers $(N=650)$} & \multicolumn{5}{|c|}{ Stayers $(N=650)$} & \multirow[b]{2}{*}{ Diff in mean } \\
\hline & mean & median & $s d$ & $\min$ & $\max$ & mean & median & $s d$ & $\min$ & $\max$ & \\
\hline No. of publications & 1.52 & 1 & 2.47 & 0 & 24 & 1.60 & 1 & 3.00 & 0 & 46 & -0.08 \\
\hline No. of citations & 7.40 & 0 & 18.30 & 0 & 220 & 8.02 & 0 & 22.04 & 0 & 260 & -0.62 \\
\hline Cum. no. of publications & 10.34 & 4 & 18.20 & 0 & 211 & 10.46 & 4 & 18.40 & 0 & 214 & -0.11 \\
\hline Cum. no. of citations & 53.92 & 7 & 128.61 & 0 & 1507 & 54.69 & 7 & 133.53 & 0 & 1559 & -0.76 \\
\hline Age & 45.31 & 44 & 10.47 & 23 & 69 & 44.86 & 43 & 10.07 & 23 & 73 & 0.45 \\
\hline Years since receiving degree & 10.50 & 8 & 9.21 & 0 & 38 & 9.21 & 7 & 7.85 & 0 & 37 & $1.29 * * *$ \\
\hline Male & 0.61 & 1 & 0.49 & 0 & 1 & 0.61 & 1 & 0.49 & 0 & 1 & 0.00 \\
\hline Children & 0.89 & 0 & 1.05 & 0 & 4 & 0.80 & 0 & 1.02 & 0 & 5 & 0.08 \\
\hline Married/Cohabitating & 0.68 & 1 & 0.47 & 0 & 1 & 0.67 & 1 & 0.47 & 0 & 1 & 0.01 \\
\hline Full Professors & 0.22 & 0 & 0.41 & 0 & 1 & 0.22 & 0 & 0.41 & 0 & 1 & 0.00 \\
\hline Associate Professors & 0.30 & 0 & 0.46 & 0 & 1 & 0.30 & 0 & 0.46 & 0 & 1 & 0.00 \\
\hline Postdocs & 0.04 & 0 & 0.19 & 0 & 1 & 0.04 & 0 & 0.19 & 0 & 1 & 0.00 \\
\hline Guest researchers & 0.36 & 0 & 0.48 & 0 & 1 & 0.36 & 0 & 0.48 & 0 & 1 & 0.00 \\
\hline 'Other' researchers & 0.08 & 0 & 0.28 & 0 & 1 & 0.08 & 0 & 0.28 & 0 & 1 & 0.00 \\
\hline
\end{tabular}

Note: Each researcher is averaged into one observation. 


\section{APPENDIX TABLE C2}

Main effect of mobility: fixed effect, matched sample

\begin{tabular}{lcc}
\hline Variables & $(1)$ & $(2)$ \\
PostMob & Publications & Citations \\
& $0.199 * * *$ & $0.446^{* * *}$ \\
& $(0.0491)$ & $(0.129)$ \\
Observations & & 7,550 \\
Number of individuals & 8,487 & 927 \\
Time-varying controls & 1,052 & Yes \\
Time-fixed controls & Yes & No \\
Individual FE & No & Yes \\
Estimation method & Yes & Poisson \\
\hline \multicolumn{1}{c}{ Note: Robust standard errors clustered at the individual level in parenthesis. *** $<<0.01, * *$} \\
$\mathrm{p}<0.05, * \mathrm{p}<0.1$. & Poisson &
\end{tabular}




\section{APPENDIX TABLE C3}

Effect of career transitions and moving: fixed effects, matched sample

\begin{tabular}{|c|c|c|}
\hline Variables & $\begin{array}{c}\text { (1) } \\
\text { Publications }\end{array}$ & $\begin{array}{c}\text { (2) } \\
\text { Citations } \\
\end{array}$ \\
\hline PostMob \& No Promotion/Demotion & $\begin{array}{c}0.239 * * * \\
(0.0720)\end{array}$ & $\begin{array}{c}0.496^{* * *} \\
(0.139)\end{array}$ \\
\hline PostMob \& Promotion & $\begin{array}{c}0.194 * * * \\
(0.0690)\end{array}$ & $\begin{array}{c}0.262 * * \\
(0.127)\end{array}$ \\
\hline Stay \& Promotion & $\begin{array}{l}0.0967^{*} \\
(0.0579)\end{array}$ & $\begin{array}{c}0.130 \\
(0.115)\end{array}$ \\
\hline PostMob \& Demotion & $\begin{array}{l}0.284 * \\
(0.171)\end{array}$ & $\begin{array}{l}0.910^{*} \\
(0.477)\end{array}$ \\
\hline Stay \& Demotion & $\begin{array}{l}0.0971 \\
(0.127)\end{array}$ & $\begin{array}{l}0.503 * \\
(0.262)\end{array}$ \\
\hline $\begin{array}{l}\text { Tests equality of coefficients } \\
\text { PostMob \& No Promotion/Demotion vs. } \\
\text { PostMob \& Promotion }\end{array}$ & 0.20 & 1.43 \\
\hline PostMob \& Promotion vs. Stay \& Promotion & 2.10 & 0.81 \\
\hline Observations & 8,487 & 7,550 \\
\hline Number of individuals & 1,052 & 927 \\
\hline Time-varying controls & Yes & Yes \\
\hline Time-fixed controls & No & No \\
\hline Individual FE & Yes & Yes \\
\hline Estimation method & Poisson & Poisson \\
\hline
\end{tabular}




\section{APPENDIX TABLE C4}

Effect of moving and university hierarchies: fixed effects, matched sample

\begin{tabular}{|c|c|c|}
\hline Variables & $\begin{array}{c}\text { (1) } \\
\text { Publications }\end{array}$ & $\begin{array}{c}\text { (2) } \\
\text { Citations }\end{array}$ \\
\hline University to university & $\begin{array}{c}0.225 * * * \\
(0.0596)\end{array}$ & $\begin{array}{c}0.519 * * * \\
(0.149)\end{array}$ \\
\hline Uni. College to Uni. College & $\begin{array}{c}0.167 \\
(0.147)\end{array}$ & $\begin{array}{l}-0.0700 \\
(0.283)\end{array}$ \\
\hline Uni. College to University & $\begin{array}{c}0.174 * \\
(0.0961)\end{array}$ & $\begin{array}{l}-0.102 \\
(0.124)\end{array}$ \\
\hline University to Uni. College & $\begin{array}{c}0.167 \\
(0.104)\end{array}$ & $\begin{array}{c}0.267 \\
(0.265)\end{array}$ \\
\hline $\begin{array}{l}\text { Tests equality of coefficients } \\
\text { University to university vs. Uni. College to } \\
\text { Uni. College }\end{array}$ & 0.14 & $3.87 * *$ \\
\hline $\begin{array}{l}\text { Uni. College to University vs. University to } \\
\text { Uni. College }\end{array}$ & 0.00 & 1.40 \\
\hline $\begin{array}{l}\text { University to university vs. Uni. College to } \\
\text { University }\end{array}$ & 0.21 & $11.09 * * *$ \\
\hline $\begin{array}{l}\text { Uni. College to Uni. College vs. University to } \\
\text { Uni. College }\end{array}$ & 0.00 & 0.73 \\
\hline Observations & 8,487 & 7,550 \\
\hline Number of individuals & 1,052 & 927 \\
\hline Time-varying controls & Yes & Yes \\
\hline Time-fixed controls & No & No \\
\hline Individual FE & Yes & Yes \\
\hline Estimation method & Poisson & Poisson \\
\hline
\end{tabular}




\section{APPENDIX TABLE C5}

Effect of mobility within disciplines: fixed effects, matched sample

\begin{tabular}{|c|c|c|}
\hline Variables & $\begin{array}{c}\text { (1) } \\
\text { Publications } \\
\text { Fixed effects } \\
\end{array}$ & $\begin{array}{c}\text { (2) } \\
\text { Citations } \\
\text { Fixed effects }\end{array}$ \\
\hline Social sciences/Humanities & $\begin{array}{l}-0.376 * * * \\
(0.126)\end{array}$ & $\begin{array}{c}-0.793 * * * \\
(0.294)\end{array}$ \\
\hline $\begin{array}{l}\text { Observations } \\
\text { Number of individuals }\end{array}$ & $\begin{array}{c}2,286 \\
274\end{array}$ & $\begin{array}{c}1,742 \\
208\end{array}$ \\
\hline Medicine & $\begin{array}{l}0.207 * * * \\
(0.0698)\end{array}$ & $\begin{array}{c}0.256 * * \\
(0.110)\end{array}$ \\
\hline $\begin{array}{l}\text { Observations } \\
\text { Number of individuals }\end{array}$ & $\begin{array}{c}2,468 \\
332\end{array}$ & $\begin{array}{c}2,413 \\
320\end{array}$ \\
\hline Natural sciences & $\begin{array}{l}0.211 * \\
(0.117)\end{array}$ & $\begin{array}{l}0.442 * * * \\
(0.158)\end{array}$ \\
\hline $\begin{array}{l}\text { Observations } \\
\text { Number of individuals }\end{array}$ & $\begin{array}{l}1,472 \\
219\end{array}$ & $\begin{array}{l}1,401 \\
205\end{array}$ \\
\hline Engineering/Technology & $\begin{array}{l}0.237 * * \\
(0.0956)\end{array}$ & $\begin{array}{c}0.550 * * \\
(0.225)\end{array}$ \\
\hline $\begin{array}{l}\text { Observations } \\
\text { Number of individuals }\end{array}$ & $\begin{array}{c}2,159 \\
284\end{array}$ & $\begin{array}{l}1,878 \\
242\end{array}$ \\
\hline $\begin{array}{l}\text { Time-varying controls } \\
\text { Time-fixed controls } \\
\text { Individual FE } \\
\text { Estimation method }\end{array}$ & $\begin{array}{c}\text { Yes } \\
\text { No } \\
\text { Yes } \\
\text { Poisson }\end{array}$ & $\begin{array}{c}\text { Yes } \\
\text { No } \\
\text { Yes } \\
\text { Poisson }\end{array}$ \\
\hline
\end{tabular}




\section{Appendix D: Estimations of IPTC weights}

\begin{tabular}{|c|c|c|}
\hline \multicolumn{3}{|c|}{$\begin{array}{c}\text { APPENDIX TABLE D1 } \\
\text { Logit estimation of probability of move }\end{array}$} \\
\hline & $(1)$ & $(2)$ \\
\hline Variables & Denominator of treatment weight & Numerator of treatment weight \\
\hline \multirow[t]{2}{*}{ Publications, t-1 } & $0.0582 * * *$ & \\
\hline & $(0.0168)$ & \\
\hline \multirow[t]{2}{*}{ Citations, $\mathrm{t}-1$} & -0.00199 & \\
\hline & $(0.00164)$ & \\
\hline \multirow[t]{2}{*}{ Cumulative Publications, t-2 } & $-0.00914 * *$ & \\
\hline & $(0.00409)$ & \\
\hline \multirow[t]{2}{*}{ Cumulative Citations, t-2 } & -0.000253 & \\
\hline & $(0.000457)$ & \\
\hline \multirow[t]{2}{*}{ Age } & $0.121 * * *$ & $0.212 * * *$ \\
\hline & $(0.0344)$ & $(0.0304)$ \\
\hline \multirow[t]{2}{*}{ Age squared } & $-0.00170 * * *$ & $-0.00257 * * *$ \\
\hline & $(0.000363)$ & $(0.000327)$ \\
\hline \multirow[t]{2}{*}{ Male } & $-0.117^{*}$ & -0.0947 \\
\hline & $(0.0695)$ & $(0.0677)$ \\
\hline \multirow[t]{2}{*}{ Number of Children } & -0.0568 & -0.0373 \\
\hline & $(0.0402)$ & $(0.0391)$ \\
\hline \multirow[t]{2}{*}{ Married } & -0.0565 & -0.0129 \\
\hline & $(0.0815)$ & $(0.0802)$ \\
\hline Observations & 80,772 & 92,436 \\
\hline Field FE & Yes & Yes \\
\hline University FE & Yes & Yes \\
\hline Position FE & Yes & Yes \\
\hline Year FE & Yes & Yes \\
\hline
\end{tabular}

Note: Standard errors in parentheses. ${ }^{* * *} \mathrm{p}<0.01,{ }^{* *} \mathrm{p}<0.05, * \mathrm{p}<0.1$ 
APPENDIX TABLE TABLE D2

Logit estimation of probability of exit

\begin{tabular}{|c|c|c|}
\hline Variables & $\begin{array}{l}\text { (1) } \\
\text { Denominator of censoring } \\
\text { weight }\end{array}$ & $\begin{array}{l}\text { (2) } \\
\text { Numerator of censoring } \\
\text { weight }\end{array}$ \\
\hline Publications, $\mathrm{t}-1$ & $\begin{array}{c}-0.0767 * * * \\
(0.00897)\end{array}$ & \\
\hline Citations, t-1 & $\begin{array}{c}0.00151^{* * *} * \\
(0.000507)\end{array}$ & \\
\hline $\begin{array}{l}\text { Cumulative Publications, t- } \\
2\end{array}$ & $\begin{array}{c}-0.0156^{* * *} \\
(0.00179)\end{array}$ & \\
\hline Cumulative Citations, $\mathrm{t}-2$ & $\begin{array}{c}0.000580 * * * \\
(0.000157)\end{array}$ & \\
\hline Age & $\begin{array}{c}-0.565 * * * \\
(0.0106)\end{array}$ & $\begin{array}{c}-0.504 * * * \\
(0.00759)\end{array}$ \\
\hline Age squared & $\begin{array}{c}0.00567 * * * \\
(0.000110)\end{array}$ & $\begin{array}{c}0.00499 * * * \\
(8.16 \mathrm{e}-05)\end{array}$ \\
\hline Male & $\begin{array}{c}-0.278 * * * \\
(0.0257)\end{array}$ & $\begin{array}{c}-0.422 * * * \\
(0.0212)\end{array}$ \\
\hline Number of Children & $\begin{array}{l}0.0289^{*} \\
(0.0163)\end{array}$ & $\begin{array}{l}0.0234^{*} \\
(0.0140)\end{array}$ \\
\hline Married & $\begin{array}{c}-0.0697 * * \\
(0.0306)\end{array}$ & $\begin{array}{l}-0.111 * * * \\
(0.0263)\end{array}$ \\
\hline $\begin{array}{l}\text { Observations } \\
\text { Field FE } \\
\text { University FE } \\
\text { Position FE } \\
\text { Year FE }\end{array}$ & $\begin{array}{c}80,918 \\
\text { Yes } \\
\text { Yes } \\
\text { Yes } \\
\text { Yes }\end{array}$ & $\begin{array}{c}92,403 \\
\text { Yes } \\
\text { Yes } \\
\text { Yes } \\
\text { Yes }\end{array}$ \\
\hline
\end{tabular}

Note: Standard errors in parentheses. $* * * \mathrm{p}<0.01,{ }^{*} * \mathrm{p}<0.05,{ }^{*} \mathrm{p}<0.1$ 